\title{
Hands-On Made 4 ME: Deploying, Using, Developing and Evaluating Desk- top Computer Numerical Controlled (CNC) Systems in the Engineering Class- room
}

\section{Mr. Farhan Azhar, University of Massachusetts Lowell}

Graduate Research Assistant- Mechanical Engineering at University of Massachusetts Lowell.

Mr. Kristofer Tite, University of Massachusetts, Lowell

Undergraduate mechanical engineering student at University of Massachusetts Lowell.

\section{Dr. Stephen Johnston, University of Massachusetts, Lowell}

Stephen P. Johnston is an Assistant Professor in the Department of Plastics Engineering at the UMass Lowell. His research interests include process monitoring and control for injection molding, plastic product design, and injection mold design. He is an inventor on three patents and author of over thirty publications.

Dr. Christopher Hansen, University of Massachusetts, Lowell

Dr. Sammy G. Shina, University of Massachusetts, Lowell

Sammy G. Shina, P.h.D., P.E., is the professor of Mechanical Engineering at the University of Massachusetts Lowell and has previously lectured at University of Pennsylvania's EXMSE Program and at the University of California Irvine. He is the coordinator of the Design and Manufacturing Certificate, the Quality Engineering Certificate, the ME senior Capstone Projects and COOP education at UML. He is a past chairman of the Society of Manufacturing Engineers (SME) Robotics/FMS and a founding member of the Massachusetts Quality Award. He is the founder of the New England Lead Free Consortium. $\mathrm{He}$ is the author of several best-selling books on Concurrent Engineering, Six Sigma, Green Design and Engineering Project Management. He contributed two chapters and over 170 technical publications and presentations in his fields of research.

\section{Alaina M Schiano \\ Dr. David Joe Willis, University of Massachusetts, Lowell}

David Willis is an Assistant Professor of Mechanical Engineering at UMass Lowell. His interests are in aerodynamics and engineering education. He works on projects ranging from parachutes to bio-inspired flight and CNCs in the undergraduate classroom. 


\title{
Hands-On Made 4 ME: Deploying, Using, Developing and Evalu- ating Desktop Computer Numerical Controlled (CNC) Systems in the Engineering Classroom
}

\begin{abstract}
This paper describes the Hands-On Made 4 ME project to design, use and deploy inexpensive, desktop computer numerical control (CNC) systems in mechanical engineering courses. The project examines both the deployment of off-the-shelf CNC machines as well as the development and deployment of an in-house, education specific, modular CNC building block. This modular CNC building block is designed to minimize the deployment cost in a high volume classroom environment while also minimizing the student time required to prototype and test multi-axis motion control. Initial prototyping of the modular block indicates the design is both economic and functional for educational use.

The educational impact of this paper focuses on CNC technology use in the Introduction to Mechanical Engineering course in which freshman students interact with the desktop CNC machines to complete hands-on projects several times during a semester. Weekly student surveys indicate that these hands-on, project-based CNC learning activities have a strong positive effect on student motivation.
\end{abstract}

\subsection{Introduction}

Computer numerical control (CNC) is a relatively mature method that forms the foundation of a variety of modern manufacturing technologies including: CNC milling, 3D-printing, laser cutting, plasma cutting, water-jet cutting, etc. Whether it is creating a part or product directly, or developing the tooling (e.g., molds) for higher volume manufacturing, CNC machines are ubiquitous in today's manufacturing environment and have revolutionized the way products are manufactured. Industrial scale CNC technology is expensive and requires machinists with specialized training. While it would be beneficial for all mechanical engineers to have familiarity with industrial level CNC machine programming and operation, it is challenging to integrate into the undergraduate curriculum.

With the introduction of programmable control electronics and the proliferation of personal computing, CNC based manufacturing techniques have become more accessible to the hobbyist and home user. Inexpensive CNC "making machines" possess basic functionality and often have reduced capability when compared with higher-end industrial grade machines; however, they command a significantly lower price and complexity. The availability of these hobbyist CNC solutions has spurred the ongoing "maker movement"- a robust community of hobbyists and makers who create a wide variety of systems and solutions using readily accessible electronics, mechanical systems and desktop manufacturing.

The low-cost control electronics and desktop manufacturing associated with the "maker movement" has the potential to also impact and transform the engineering classroom. Hands-on, experiential learning has a positive impact on learning ${ }^{1}$ and diversity in the classroom ${ }^{2}$. Accessible and inexpensive CNC manufacturing tools can also provide less-intimidating platforms to ex- 
plore prototype product and part development in early design phases. This also promotes a strong feedback loop between the virtual design and physical part. As is the case at other universities, the University of Massachusetts Lowell has introduced the products of the Maker Movement into the classroom, including: introducing the Arduino Uno platform, desktop CNC milling, 3D printing and laser cutting. This paper examines the integration of CNC milling in the Mechanical Engineering classroom, in particular in the critically important freshman year.

This paper highlights the deployment of inexpensive desktop CNC technology at the University of Massachusetts Lowell as well as the design, development and deployment of an educationspecific CNC modular motion block. The paper is comprised of three parts: (1) the selection and deployment of off-the-shelf, desktop CNC machines (2) the design, development and deployment of an in-house modular CNC motion block that allows students to build CNC platforms and program their own multi-axis CNC machine creations and (3) the integration of CNC platforms into mechanical engineering courses coupled with an evaluation of freshman student motivation towards performing hands-on CNC-based activities.

\section{PART I}

\subsection{Off-The-Shelf CNCs and Integration in Educational Environment}

Ten off-the-shelf, inexpensive desktop CNC systems have been deployed at the University of Massachusetts Lowell. These CNC milling/routing systems use low power rotary tools for milling softer materials such as wax, wood and plastic. While softer materials are machined, these desktop CNC systems can be used to introduce students to the basic principles of CNC manufacturing and control.

\subsection{Inexpensive, Off-The-Shelf CNC Machine Options}

There are a wide variety of inexpensive desktop CNCs on the market today. These can be classified into pre-assembled systems or kit-based systems. Kit-based CNC systems were considered for this project for two reasons:

1) Kit-based systems are less expensive than equivalently featured pre-built systems.

2) Kit-based systems can allow students to interact and learn during the assembly, modification and repair process.

The two kit-based systems that were deployed in the University of Massachusetts Lowell Mechanical Engineering courses were the (a) Zentoolworks family of CNC machines (7'x12", 7"x7" and 12" x 12" cut area, https://www.zentoolworks.com) and (b) the Inventables.com Shapeoko II system (https://www.inventables.com/projects/shapeoko-2-the-works-110v). A detailed presentation of these machines as well as the safety considerations (safety enclosures, noise limits, electrical systems, etc.) is presented in Vaillant et al. ${ }^{3-6}$

\subsubsection{Zentoolworks PVC Sheet, Threaded Rod CNC Machines}

Zentoolworks CNC machines comprise a single axis moving table ( $y$-axis) and a 2 -axis gantry ( $x$-axis and $z$-axis motions) as seen in Figure 1-a. The frame, motor mounts and axes are constructed from several non-unique, planar 2D parts that are cut from stock PVC sheet. Each axis is 
mounted on a pair of precision steel shafts with linear bearings. NEMA 17 motors are attached to the $\mathrm{CNC}$ frame and connected to threaded rods that drive each axis. The PVC parts are joined using a large number of machine screws. Each machine has a fixed cutting volume that is not easily expanded. Overall, the machine design and configuration is relatively stiff, robust and lightweight.

\subsubsection{Inventables.com Shapeoko II Belt Driven CNC Machines}

The Inventables.com Shapeoko II is a 3-axis moving gantry machine shown in Figure 1-b. The axes of this CNC platform are installed incrementally on each other forming a moving $x$-, $z$ - gantry. The $x$ - and $y$-axes are both belt driven. The axis linear motion is constrained using a track and $\mathrm{V}$-wheel guide system. The $z$-axis is driven using a threaded rod. The axes all use NEMA 17 motors for prescribed motion. The Shapeoko II platform is easily expanded to larger sizes than the baseline machine (upwards of $1.0 \mathrm{~m} \mathrm{x} 1.0 \mathrm{~m}$ base).

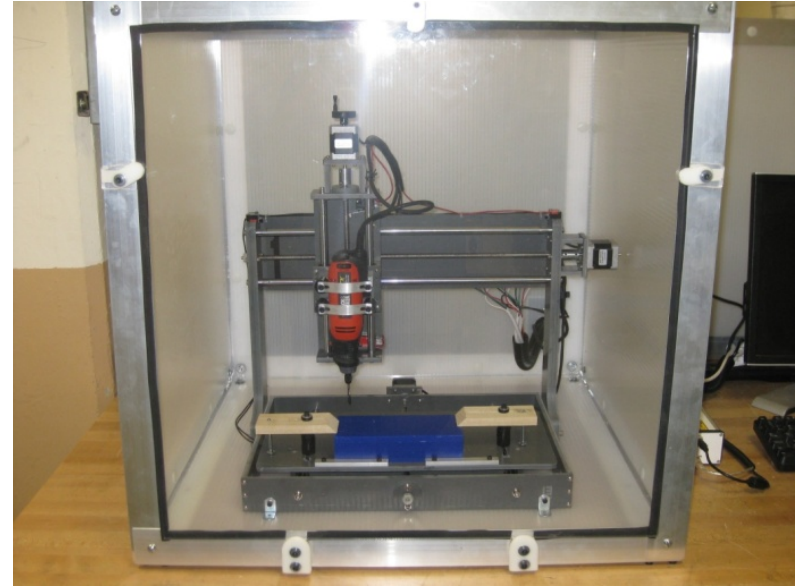

(a)

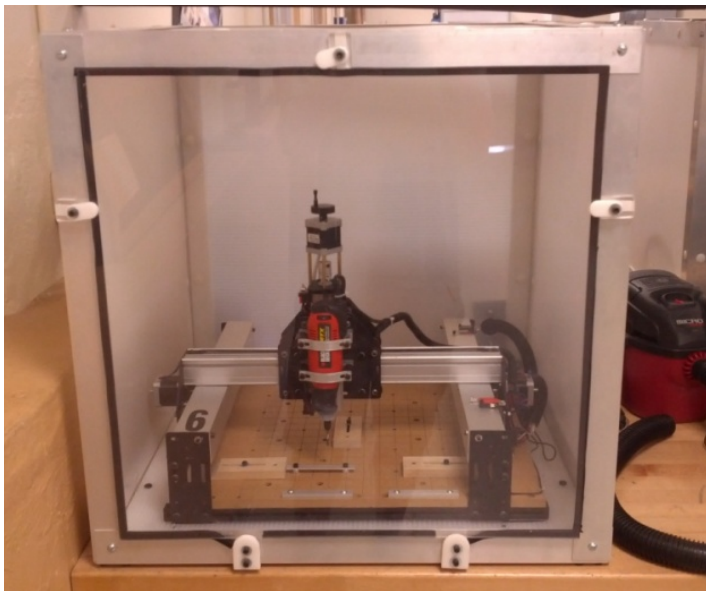

(b)

Figure 1: (a) A Zentoolworks CNC 7" x 12" table machine including a custom enclosure. (b) An Inventables.com Shapeoko II CNC machine.

\subsubsection{CNC Control Electronics}

Both the ZenToolworks and the Shapeoko II require a CNC controller whose primary purpose is to receive the $x$-, $y$ - and $z$ - coordinates from a computer and convert them into signals that drive the axes' motors. For this deployment, an Arduino UNO (https://www.arduino.cc) with a GRBL shield (https://github.com/grbl/grbl) is connected to the computer via USB cable (Figure 2). Other hobbyist CNC controllers such as the TinyG (https://www.synthetos.com/project/tinyg/) or Smoothieboard (http://smoothieware.org) could also be considered for machine control. The Arduino UNO acts as an interface between the computer and the GRBL motor controller board. The GRBL motor controller board connects to the three stepper motors on the CNC to generate the desired motor rotations. The commands from the computer are sent to the controller using some form of G-Code sender, either an open source program (e.g.: Universal G-Code Sender) or a custom program written using Matlab (Mathworks Inc., Natick, MA), Python or other programming language. 

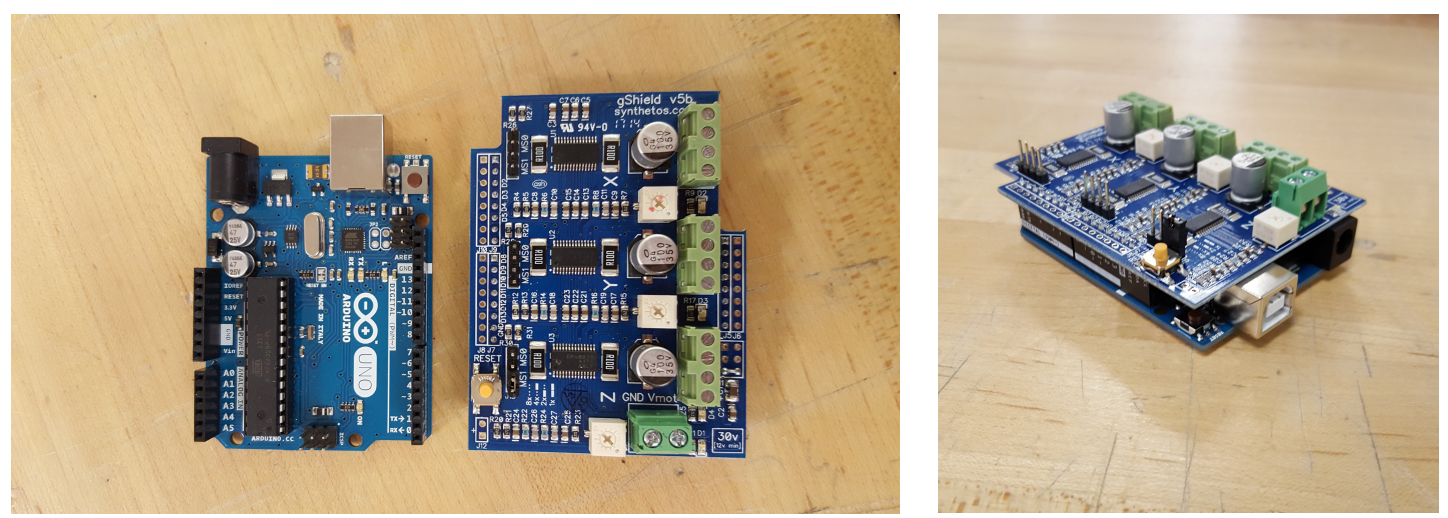

Figure 2: (a) The Arduino Uno (left) and the GRBL GShield (right) (b) The GShield mounted on the Arduino to form the controller unit.

\subsubsection{Off-The-Shelf CNC Platform Reflection}

The off-the-shelf CNC platforms that were deployed in the laboratory have been found to be effective tools for high volume classroom deployment. These CNC platforms have been used for two years in a high volume setting, with over 200 students using them per semester. Machine functionality and reliability have both been high. The machine maintenance and upgrades thus far have been relatively minor, and related to the high machine usage. For example, several CNC tables have been damaged from over-tightening materials when starting a manufacturing job or from inappropriately removing parts post-machining. Similarly, several CNC tables have also been damaged from tool contact during milling - where the $z$-axis motions were accidentally programmed to interfere with the table. This minor damage, when the result of student interactions, is also usually a positive learning experience for students who may lack expertise with CNC machines. The lower-cost and lower-complexity CNC platform also reduces the anxiety and intimidation that an industrial grade machine might produce.

\section{PART II}

\subsection{The design, development and deployment of an education-specific CNC}

Although existing off-the-shelf CNC kits have been successfully deployed in the classroom, the time required to assemble and deploy a large number of these machines can be untenable, especially when dedicated laboratory support is not available. ${ }^{3-6}$ A person familiar with the assembly process should be able to assemble a fully operational kit CNC in three to five hours; however, an inexperienced student could easily take well over twelve hours to assemble both the mechanical and electrical system (including comprehensive safety enclosures). The significant time investment is predominantly due to the large number of unique parts and detailed assembly instructions and process. The person assembling the machine needs to sort, connect and assemble these parts in the correct order. Despite best efforts, reading and following assembly instructions, the process can be time consuming for students who have limited familiarity with the assembly.

In an educational setting the design requirements are slightly different than in the maker or hobbyist community. The goal of the educational environment is to enhance student learning and 
minimize time spent on mundane tasks. To more fully engage students in the assembly and CNC design process, a series of design requirements were formed for a new educational based CNC platform $^{7,8}$ :

1) Reduce CNC machine assembly time: The primary goal of the in-house CNC design is to reduce the assembly time for a fully functional $\mathrm{CNC}$ machine to a single lab period (approximately two hours). By reducing assembly time, students could realistically design, build and use their own $\mathrm{CNC}$ machines in the laboratory and iteratively improve the design over the course of the semester.

2) Reduce or maintain the overall CNC machine cost: In higher volume educational environments, savings are typically multiplicative. Savings via bulk purchases as well as lower cost fabrication techniques can dramatically impact volume deployment costs. Minimization of the number of parts that need to be machined or processed can also present a source of savings.

3) Allow students to explore multiple CNC configurations: The goal of the CNC machine classroom deployment is to engage students in creative processes in design and manufacturing. This design requirement implies a modular $\mathrm{CNC}$ solution rather than a specific CNC platform design. A modular design would allow Cartesian ${ }^{3}$ (moving gantry as well as moving table configurations $^{3}$ ) as well as Delta machine ${ }^{3}$ configurations.

These design requirements were used to drive the team's in-house design philosophy. Rather than designing a specific $\mathrm{CNC}$ platform, the design team considered the basic building units for a CNC machine and attempted to define the minimum modular unit that could satisfy the design requirements. The team identified and focused on a single-axis of motion as the base design unit. After this, the assembly of a functional CNC machine would require a robust and modular connection between axes. With this in mind, a single axis, appropriately arranged and replicated 3times, could produce 3 -axes of independent motion. Focusing only on a single modular axis, the following design specifications were defined for a $\mathrm{CNC}$ axis:

1) Minimal single-axis part count (design goal: $<\mathbf{1 0}$ unique parts): Reducing part count (a) minimizes the assembly complexity, (b) reduces part fabrication time, (c) minimizes part storage requirements, (d) reduces the complexity of assembly instructions and (e) results in a higher degree of modularity. This minimal part count also reduced the cost of a machine - maintaining and using a lower number of parts results in significant downstream savings.

2) Minimal number of custom parts (design goal: 1 unique, modular part): Minimizing the number of custom parts reduces assembly time and parts fabrication time. For example, a single multi-functional modular part is more easily manufactured in a high volume environment, such as injection molding, than many smaller machine specific parts. If this design specification were successfully satisfied, then injection molding the one custom part would be a realistic goal.

3) Common, and easily sourced OTS parts (design goal: with the exception of one modular in-house part, each part can be sourced from $>5$ vendors): Designing a platform that can 
directly use common stock components can greatly reduce the cost of parts as well as time and cost associated with material preparation. Having multiple vendor options allows for reduced large-scale deployment costs. A savings of $\$ 10$ per axis can translate into a project deployment savings of $\$ 1,500$ when fifty 3 -axis machines are being constructed. Some common parts include: fasteners, shafts, couplers and motors.

\section{4) Flexible Functionality (goal: the design permits multiple machine/axis configurations):}

The CNC solution should provide design flexibility and problem solving opportunities for students. The platform should have a reasonable accuracy, functionality and opportunity for creative assemblies/configurations of $\mathrm{CNC}$ axes.

This series of design specifications led to a design that focused on a single "modular CNC block" that could serve to (a) produce and guide linear axis motion, (b) provide the ability to join different axes together at 90 degree angles, (c) hold the axis drive motor and the CNC tool (e.g.: extruder, spindle, etc), (d) provides sites for easy connection of motor wires to the control system, (e) provide functionality for belt and threaded rod driven systems as well as fastening. The result of the in-house design process is a CNC comprised of a series of modular blocks (Figure 3 a-f) that are easy to assemble, are low-cost, and are constructed from similar parts. These CNC blocks permit the assembly of multiple different CNC configurations.

Unlike most off-the-shelf CNC machines this modular block design allows for relatively quick assembly time. Students should be able to complete construction of a full CNC machine in one lab period, thereby giving them significantly more time to explore programming and manufacturing. In addition, the student(s) should be able to implement assembly design modifications relatively quickly or test several designs during the course of the semester. The only fabricated component of this CNC machine is the modular block itself. All other components can be readily purchased in bulk from a retailor thus reducing the cost for organizations that plan to use this in the classroom. The remainder of this section discusses the design, development and manufacture of the modular block.

The modular block (figure 3 a-f) is designed as a two-part symmetric clamshell. Each part is comprised of an internal face (figure 3 a-c) and an external face (figure $3 \mathbf{d - f}$ ). The internal face of the clamshell contains the shaft guide channels and drive channels for threaded $\mathrm{rod} / \mathrm{belt}$ drive (Figure 3 b). The external side of the block (figure 3 e) has ribs and bosses to strengthen the plastic part.

To assemble a single axis, two halves of the clamshell are joined at the internal faces and fastened together using corner fasteners to form a modular block. Each half of the clamshell supports the linear motion of the block on internal guide rails that surround the motor installation cutout. The internal guides contain recesses to install bushings that permit the precision rods to slide easily through the block. A separate rectangular channel is included to provide unobstructed passage of the drive belt or drive threaded rod. The features on the external side of an individual block (Figure 3e) are dependent on manufacturing method - with three-dimensional printing and injection molding favoring a hollowed out, rib-supported design and CNC manufacturing supporting a solid block design. 


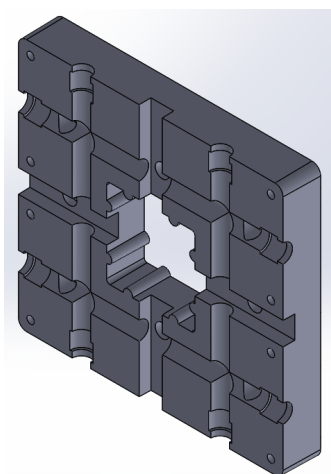

(a)

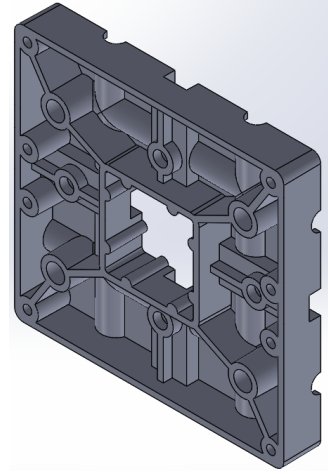

(d)

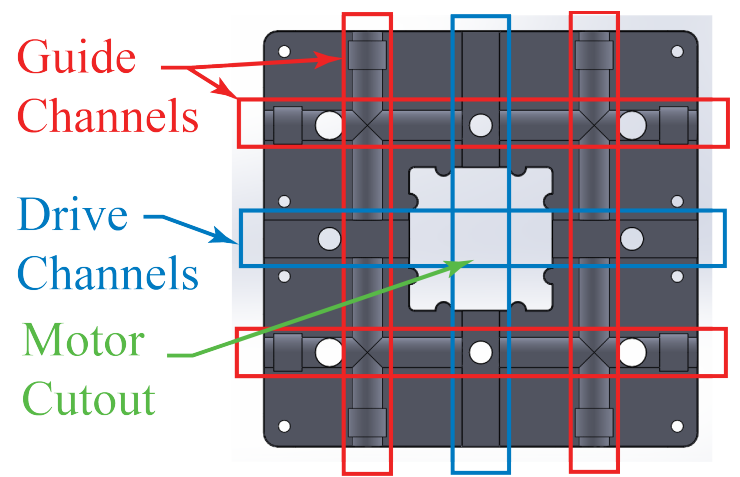

(b)

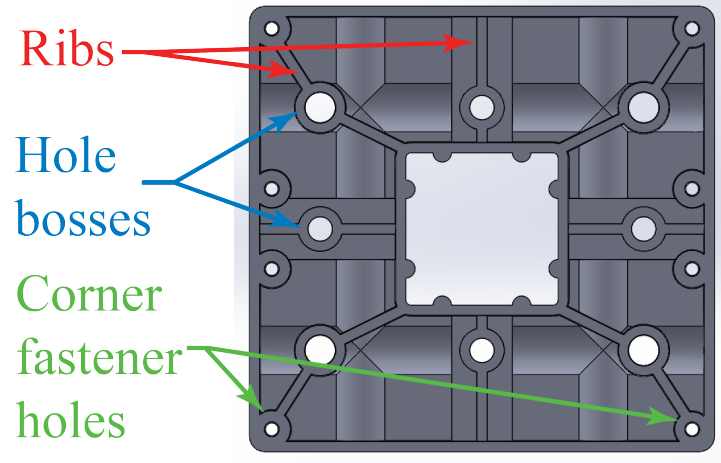

(e)

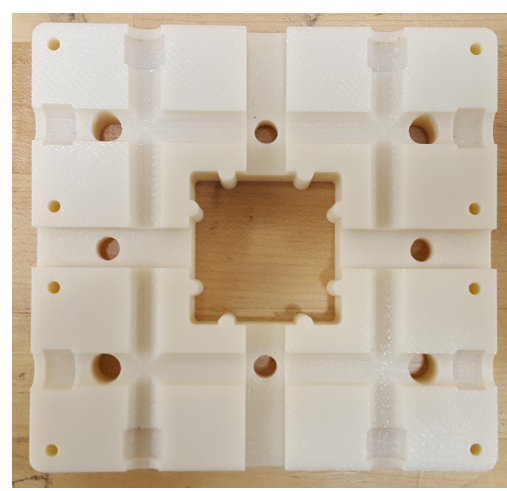

(c)

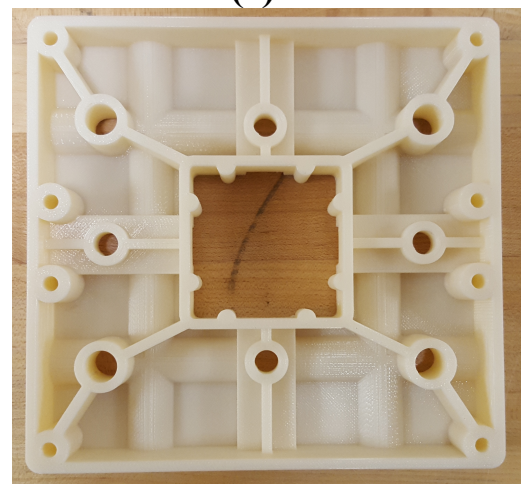

(f)

Figure 3: CAD and 3D printed prototypes of one half of the clamshell block design. Figures a-c illustrate the internal face of the clamshell block that includes the channels for the axis guide shafts and the drive system (belt or threaded rod). Figures d-f illustrate the structure on the external face to minimize material usage while maintaining a rigid and strong design. (c) and (f) are photographs of a $3 \mathrm{D}$ printed prototype.

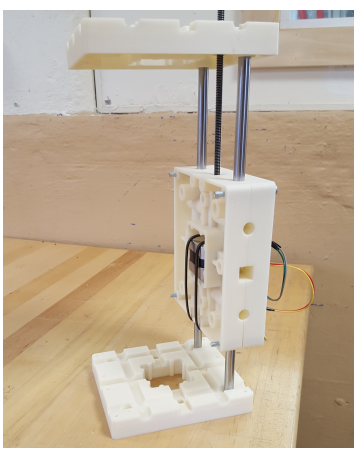

(a)

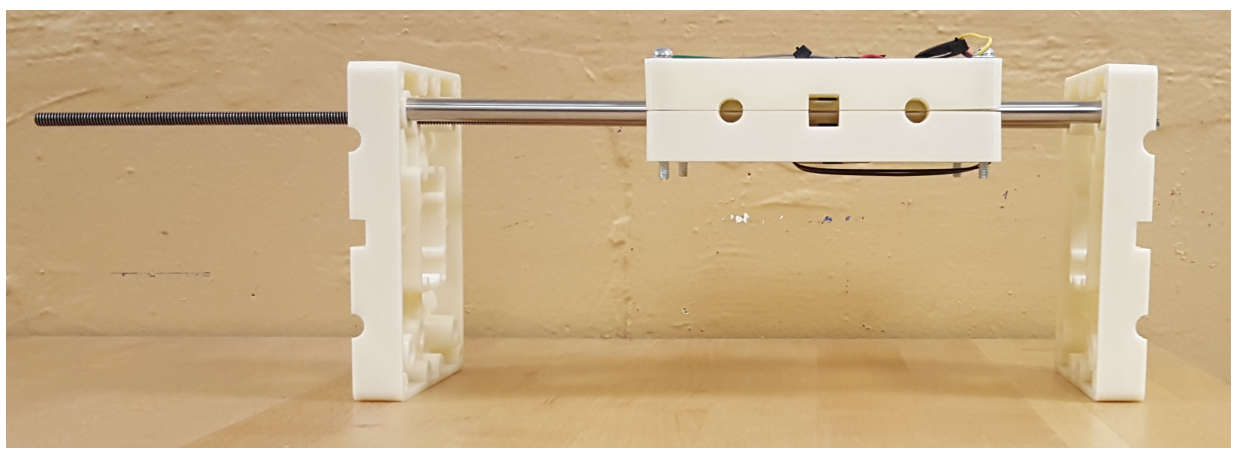

(b)

Figure 4: A single axis comprised of a modular block that traverses the axis between the two end blocks. Here only 1-end block is used; however, in a standard configuration, two end blocks would be used. (a) The axis shown in a vertical orientation, (b) the axis shown in a horizontal orientation.

Each axis of the machine is assembled in a similar manner. The motion block is mounted on the guide rails and a drive system (threaded rod or belt) is installed. The axis extents are fixed into 
the block using the holes perpendicular to the internal and external block faces as shown in Figure 4.

The clamshell design results in a single part that has low manufacturing complexity - in the simplest case, block fabrication can be performed from a single side machining process (in the case of a CNC fabrications, this would involve machining the shaft tracks, the drive tracks, the motor cutout, the axis fixture holes and the fastener holes) or using a "simple" 2-part injection mold. This fabrication simplicity is critical to ensuring lower cost tooling in volume fabrication.

Since each axis of the machine possesses the same design philosophy, it is easy to add new motion axes by simply affixing them to the existing axes modular blocks. Figure 5 illustrates one possible 3-axis CNC configuration that is assembled using a number of modular blocks, off-theshelf shafts, bushings, NEMA 17 motors and fasteners. The modular blocks serve as connections between axes as well as guides for linear motions.

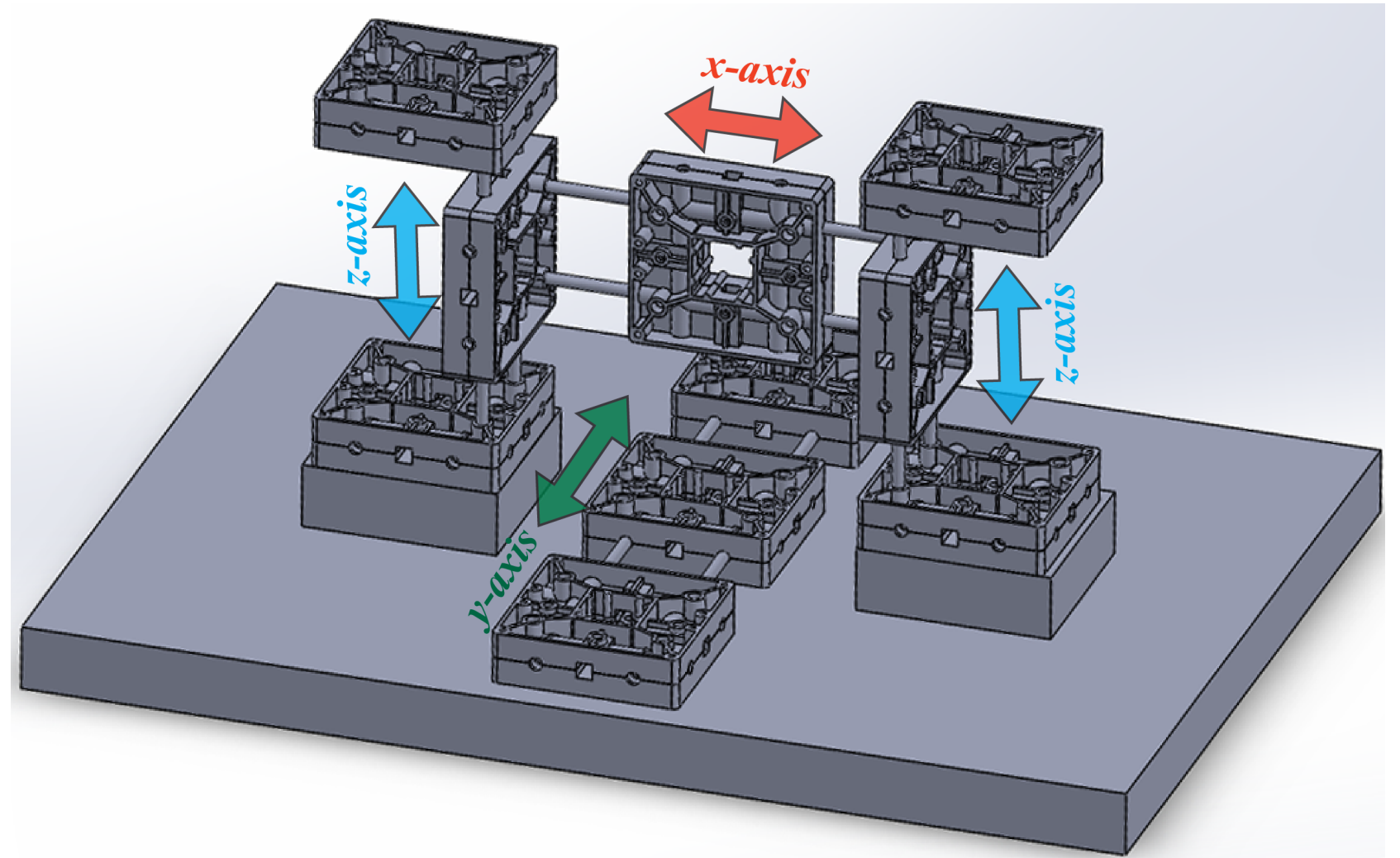

Figure 5: A CAD rendering of the CNC motion block used in one of many potential 3-axis CNC configurations.

\subsection{Detailed features of the block design}

This section explores the modular block design details starting with the motor, then the drive system, the axis guide rail system and the axis-to-block attachment. 


\subsubsection{Motor options and block installation}

The core of the CNC block is designed to house a NEMA 17 motor. The motor is in the center of the CNC block, where it generates axis motion. The motor cutout has an air-gap between the motor and block for cooling. Either captive (Figure 6-a) or non-captive (Figure 6-b) NEMA 17 motors can be used. Although a non-captive motor is a more expensive option, the threaded rod remains stationary resulting in a compact and cleaner axis design.

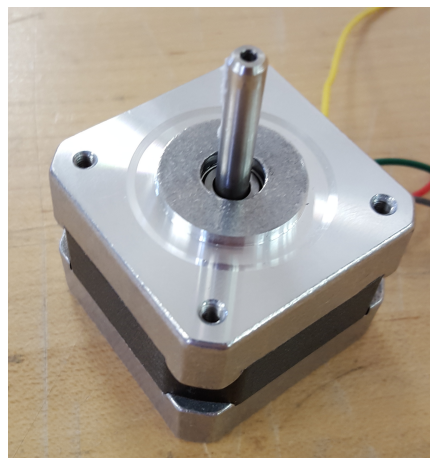

(a)

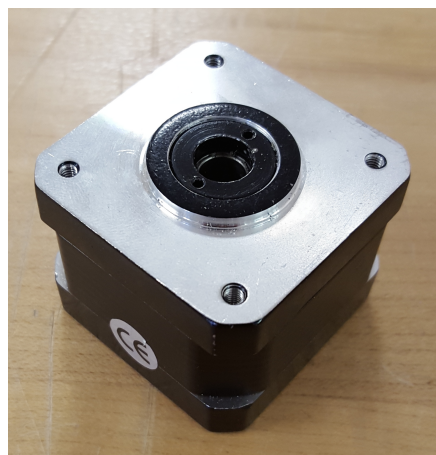

(b)

Figure 6: (a) A traditional NEMA 17 captive stepper motor has a motor shaft that rotates. (b) A non-captive stepper motor has a threaded rod that passes through a tapped hollow motor shaft, resulting in a linear actuator.

A motor cutout on the modular block facilitates the motor installation and 4-corner block fixture nuts-and-bolts that can be used to connect the motor wires to the controller board wires. The motor is easily secured in the block's cutout using a pair of zip-ties or pipe clamps as illustrated in Figure 7.

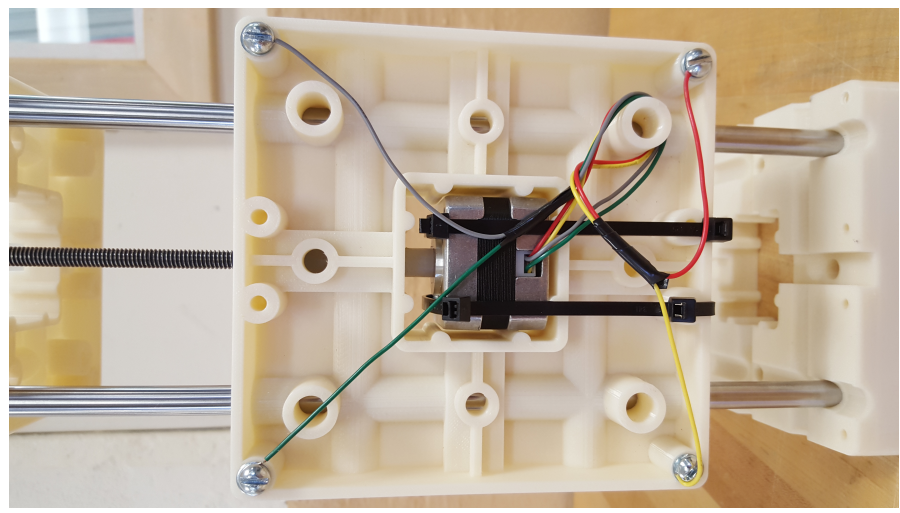

(a) (b)

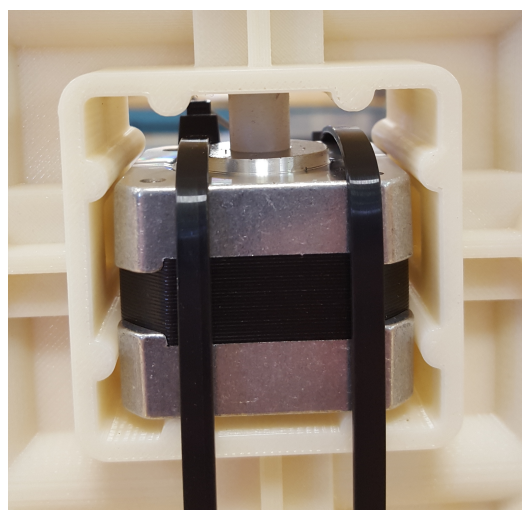

Figure 7: (a) The installation of a NEMA 17 motor in the CNC modular motion block. The block corner fasteners can be used to connect the motor to the controller. (b) A close-up of the motor installation shows the space between the top of the motor and the block.

\subsubsection{Axis Drive System Options}

By virtue of the modular design, several approaches can be used to drive axis motion including: (a) a non-captive motor with a threaded rod (b) a captive motor with a rotating threaded rod and 
(c) a belt-pulley drive system. In order to accommodate these different motion drive options, there is a channel in the block face that permits passage of both belts and 1/4" drive shafts as shown in Figure 8.

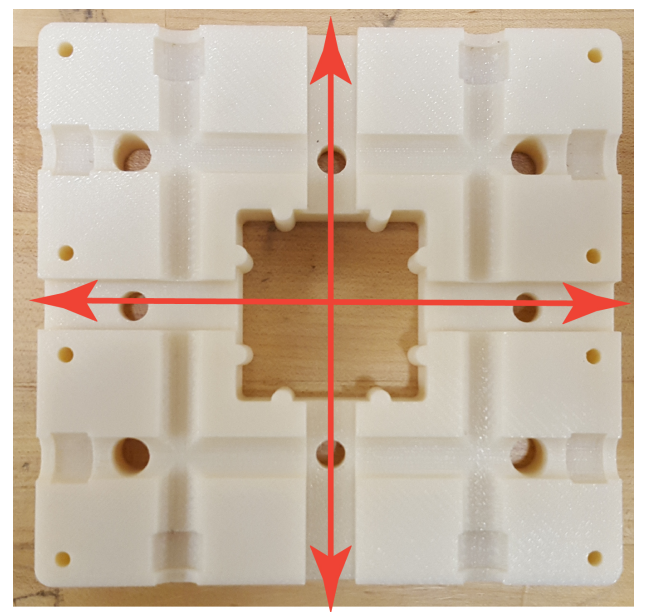

Figure 8: The central block channels are designed to allow drive shafts and belts to pass.

The non-captive motor with a threaded rod is the most elegant solution to axis motion; however, it also represents the most expensive option. In this axis-drive approach, the threaded rod is fixed by the two end-blocks and the motor rotates up-and-down on the threaded rod. With a fixed threaded rod and moving motor, no shaft coupler is required, thereby reducing the unique part count. In addition, the stationary threaded rod does not need to be considered as a potential protuberance from the block(s).

A captive motor with a $1 / 4$ "-20 threaded rod is a good balance between cost, functionality and design. The captive motor requires a shaft coupler to join the motor to the threaded rod. This shaft coupler must be low form factor so that it fits easily inside the block drive channel. Figure 9a shows a traditional small diameter metal shaft coupler; however, a nylon coupler may also be used as shown in Figure 9b. The nylon coupler is a modified 1/4"-20 spacer which is a cheap coupling solution that disconnects the motor from the drive shaft if an axis were to become stuck or jammed. In addition to the introduction of a shaft coupler, an anti-backlash drive nut is designed into the block to maintain accuracy when the axis changes directions. The anti-backlash nut design comprises two square nuts that are recessed in the block drive axis channel as shown in Figure 9c. This drive approach is cost effective; however, since the threaded rod driving the axis rotates, it will extend out of the block when the drive and anchor axis are close to each other, resulting in a slightly less elegant solution. 


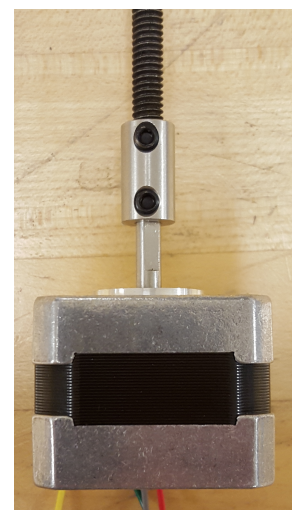

(a)

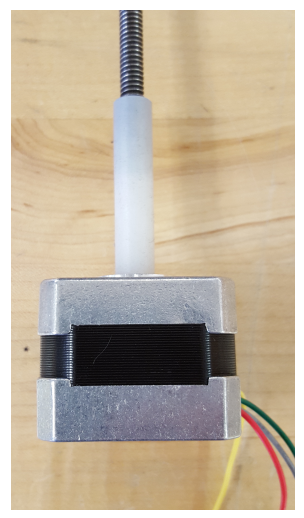

(b)

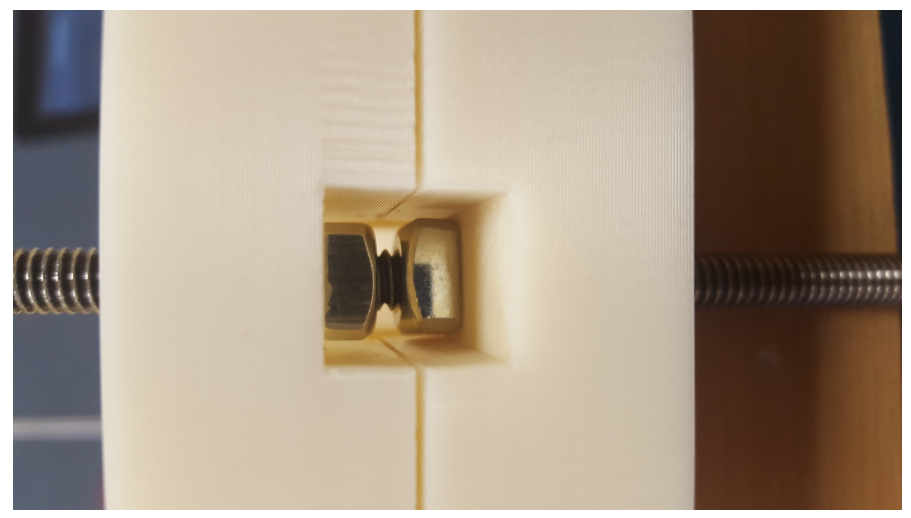

(c)

Figure 9: (a) A threaded rod attached to a captive NEMA 17 stepper motor using a low form factor metal shaft coupler. (b) The same motor attached to the threaded drive rod using a nylon spacer and (c) a belt drive configuration on a captive NEMA 17 motor.

The final configuration option for driving axis motion is a belt and pulley. This approach is similar to the non-captive motor in that a belt is fixed between two axes and a geared pulley system is used to drive the axis motions. On the two ends of the block there are fixture holes to install a belt clamp (see Figure 10).

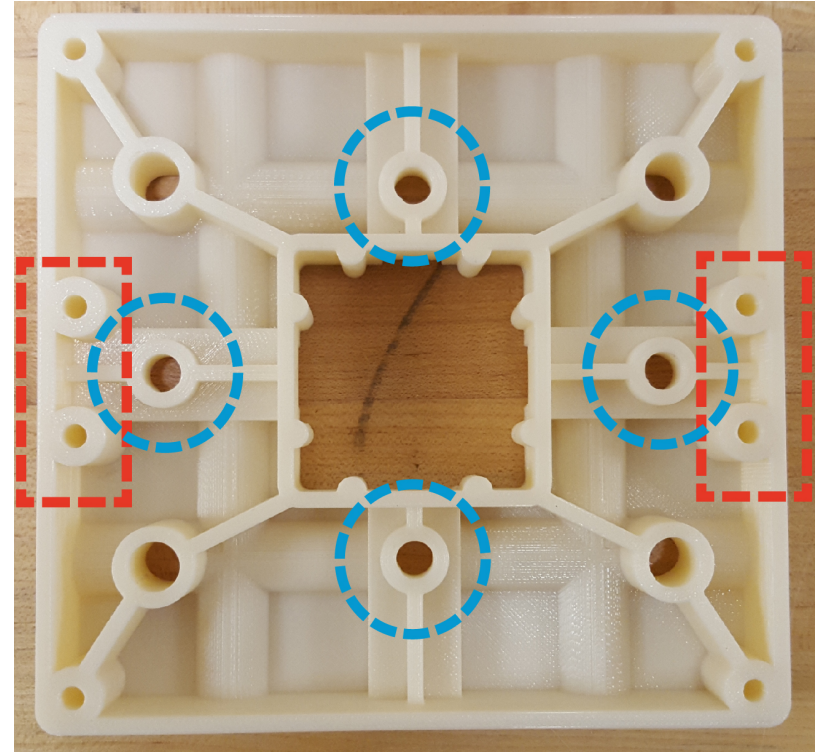

Figure 10: The block has belt specific design features including fastener holes to mount belt clamp plates (red dashed rectangles) and holes to insert spacers to guide the belt in the channel (blue dashed circles).

\subsubsection{Linear Axis Motion Guide Rails}

The axis linear motion is supported using $3 / 8$ " diameter steel shafts. Steel shafts are available in standard 12" or 18 " lengths to achieve the desired working-volume of the CNC machine. The modular block has 4-cylindrical section guide channels to support the axis sliding motion. Nylon 
bushings are used to ensure smooth sliding between the steel shafts and the block. Bushings were selected over linear bearings to reduce axis cost. In order to secure the bushings, recesses were incorporated into the cylindrical channels as shown in Figure 11-a. The guide shaft, bushing and block assembly is illustrated in Figure 11-b.

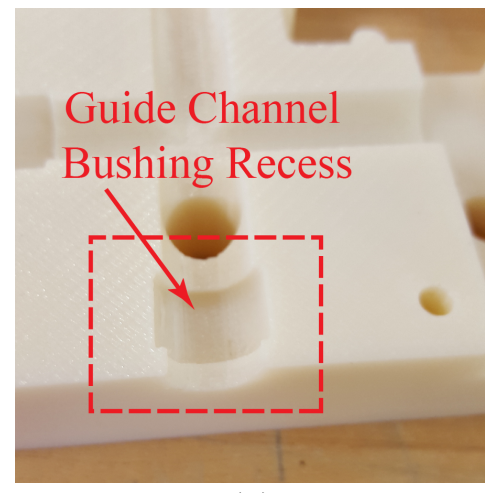

(a)

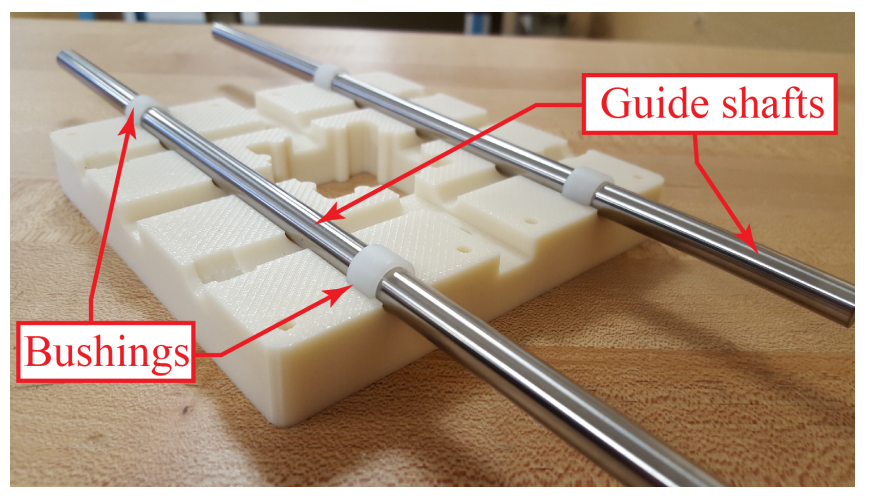

(b)

Figure 11: The block includes 4 channels for axis motion guide shafts. (a) Close-up of the guide channel showing a recess for the shaft bushing and (b) the block with the bushings and guide shafts installed. A second block is placed on top of this assembly to form a complete block.

The cylindrical shaft guide channels can also be used to fix an axis by inserting a neoprene or rubber sheet between the shaft and the channel before the block-clamshell is assembled. This approach provides a non-sliding or constrained axis if the machine design requires an axis without motion.

\subsubsection{Connecting Axes}

Press-fitting the axis steel shafts into the shaft mounting holes in the block connects the CNC axes (see Figure 12). The same distance separates these through holes as the guide rails. The press-fit used to join axes provides a unique self-destruct safety feature if the CNC motions are prescribed beyond the axis limits. The press fit is designed to slide causing an axis separation rather than catastrophic machine/axis failure.

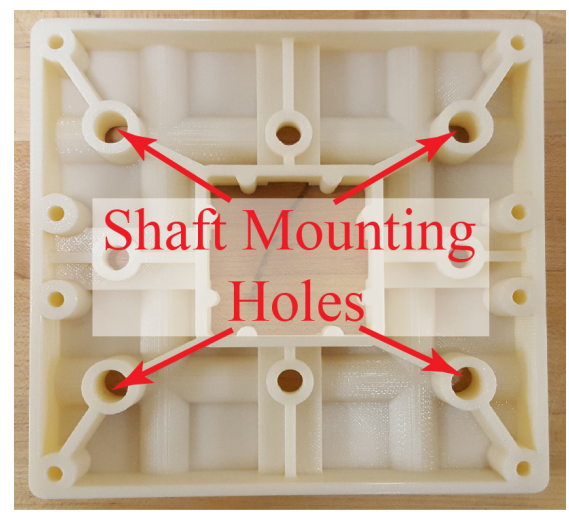

(a)

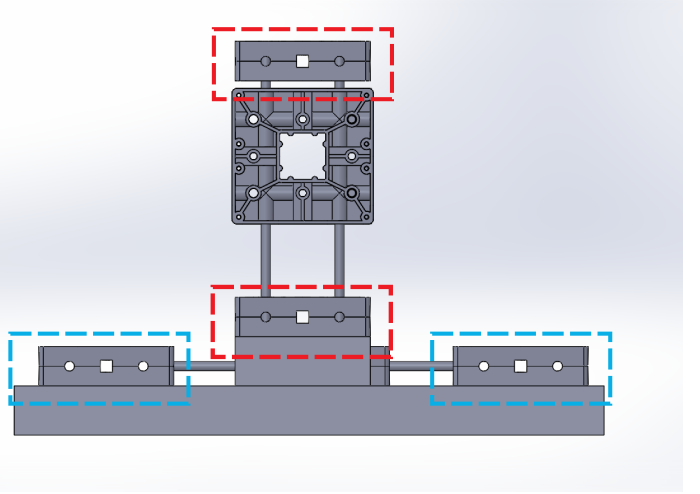

(b)

Figure 12: (a) The connecting axes (b) The axes can be connected by press fitting shafts in the mounting holes (red rectangles) or by constraining them in guide channels (blue rectangles). 


\subsubsection{Electrical System Design}

Figure 2 shows the electrical components required to control the motor. The Arduino Uno was used as the microcontroller and a grblShield is used as the motor controller. A simple custom electrical enclosure will be fabricated using sheet plastic stock material.

\subsection{Multiple manufacturing methods for single block}

The modular block has been designed so that it can be manufactured using several different manufacturing techniques - depending on the manufacturing method available at the deployment site. This flexibility in manufacturing supports the off-site deployment and broader dissemination of this design. The simple clamshell design is critical to the manufacturing method flexibility.

Additive and mold-based manufacturing techniques benefit from the minimal-material block design. By removing material, not only is the block manufactured more rapidly, it also reduces the raw material cost to manufacture. To improve structural rigidity and reduce the use of materials, ribs and bosses have been implemented in this minimal-material design as shown in Figure 3. In an injection molding setting, the placement of the ribs also reduces the risk of weld line failure. These minimum material features are not necessary for $\mathrm{CNC}$ milling or other subtractive manufacturing techniques.

\subsubsection{Three-Dimensional Printing}

The minimum material version of the $\mathrm{CNC}$ block is well suited to three-dimensional printing. The design is relatively simple and uses added features (such as recesses with off-the-shelf parts) to minimize the impact of low tolerance manufacturing. For the case of manufacturing a single machine at a satellite deployment, three-dimensional printing would be an ideal manufacturing method. All of the prototypes of the modular block were 3D printed.

\subsubsection{CNC Milling}

This block can also be produced using a CNC milling process (in wood, plastic, aluminum or other convenient material). This manufacturing approach also targets low volume production. In the case of a CNC milled block, the back face of the clamshell would not be machined (i.e. the block would remain relatively solid). The CNC milling operations for the internal face of the block are relatively simple consisting of holes, motor cutouts and channels.

\subsubsection{Silicone Casting/Plastic Molding}

In settings where only a single copy of the block can be manufactured or procured, casting and molding processes may be used. A two-part silicone mold can be manufactured from a single copy of the modular block. This mold could then be used to manufacture multiple copies of the modular block using a two-part modeling compound (e.g.: Polyurethane or Epoxy with appropriate safety considerations). 


\subsubsection{High Volume Injection Molding}

Since the design relies on a single modular part, injection molding is an ideal method for volume manufacturing. Volume manufacturing here implies a minimum of thousands of parts, and potentially upwards of millions of parts. The initial cost to setup tooling for injection molding is relatively high; however, the injection molding process is relatively inexpensive on a per-part basis once high manufacturing volumes are considered. The University of Massachusetts Lowell is fortunate to have several high volume injection molding machines in the Plastics Engineering Department. A CAD rendering of the injection molding tooling and mold plates assembly is shown in Figure 13.

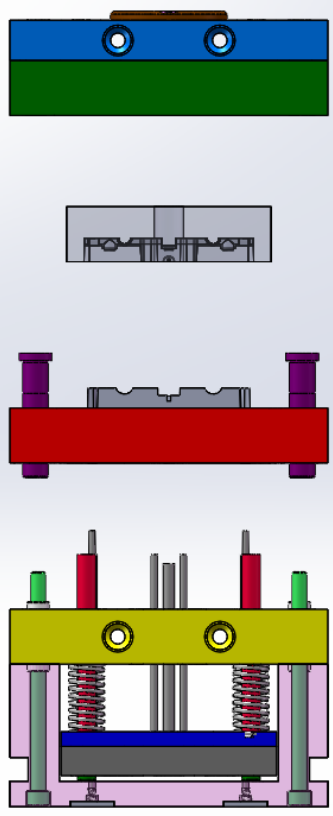

(a)

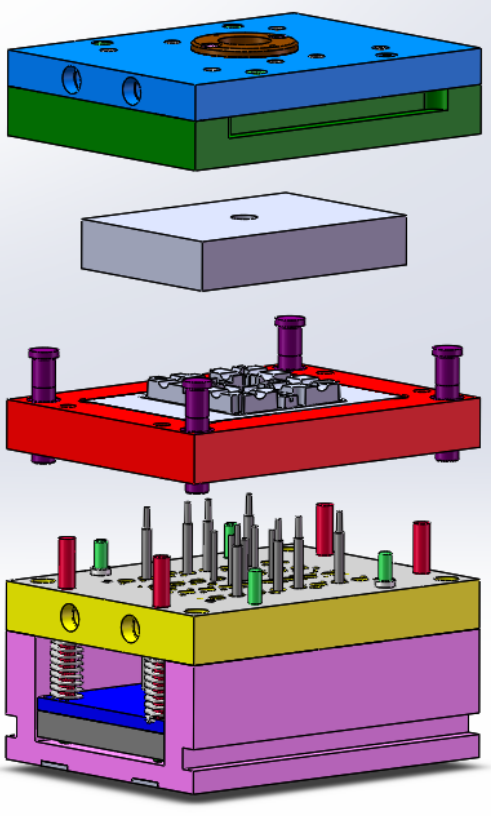

(b)

Figure 13: The injection molding tooling and mold plate assembly. The inserts (grey) are molds of the modular block component.

\subsection{Detailed Analysis of the Design}

In order to justify the cost of injection molding and ensure the success of the design, a comprehensive structural and plastic flow analysis is performed. The analysis includes a SolidWorks ${ }^{\mathrm{TM}}$ finite element structural analysis of the block under expected maximum loading conditions and a Moldflow $^{\mathrm{TM}}$ analysis. 


\subsubsection{Finite Element Analysis (FEA)}

Extensive Finite Element Analysis was performed on the block using SolidWorks ${ }^{\mathrm{TM}}$ to ensure the modular block fabricated used minimal material while maintaining adequate structural rigidity and strength. Using the injection molding manufacturing processes, upwards of 10,000-20,000 units are planned from a first version of the aluminum mold inserts. This number of units is considered a small-scale batch for traditional injection molding processes; however, even at this production scale, minimizing plastic/material usage will translate to overall manufacturing cost and time savings.

FEA was only performed on a single half-block at a time as an extreme test case. Figure 14a represents a displacement analysis of a loading condition where the NEMA 17 motor is pushing up on the motor block (orange arrows), but the block itself is constrained at the top surface (green arrows). Figure 14b shows a similar loading condition, however a stress analysis is shown. In this case the fixed positions are the bosses simulating the shafts are being held in place and the motor is trying to move down. Note that the deformations presented are scaled up for visualization purposes.

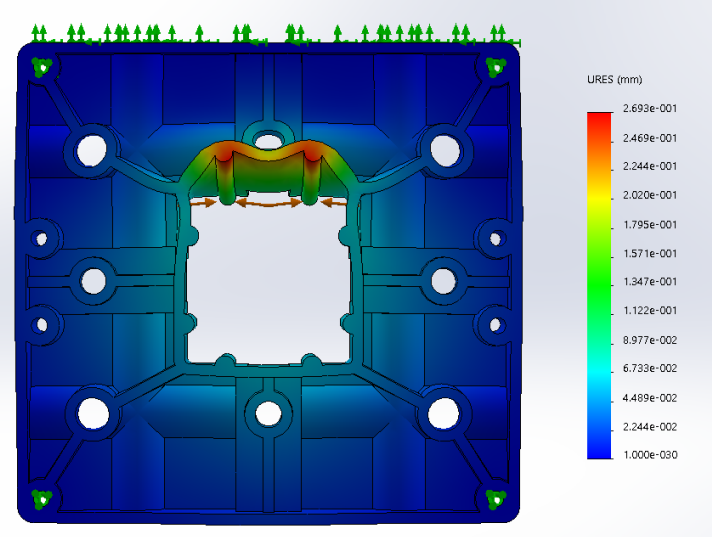

(a)

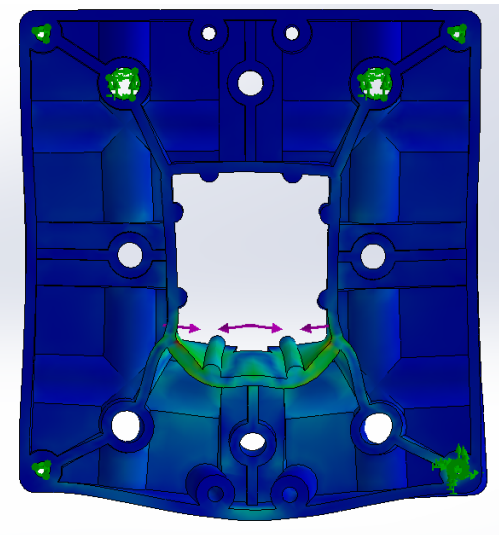

(b)

Figure 14: (a) Displacement analysis of loading condition, (b) stress analysis of loading condition.

A comprehensive suite of Finite Element Analysis cases has been performed. These FEA analyses provided guidance fro introducing strengthening ribs on the backside/outside of the part. In all cases considered, the final block design is sufficiently rigid and has sufficient strength to withstand the operational conditions expected in a laboratory setting.

\subsubsection{Moldflow ${ }^{\mathrm{TM}}$ Injection Molding Analysis}

A Moldflow ${ }^{\mathrm{TM}}$ analysis was conducted for the block mold to ensure the molding process (a) maintained safe pressures and forces below the injection molding machine's limits and (b) to ensure that the injection and flow of plastic would result in a quality molded end product. 
With user specified injection locations in Moldflow ${ }^{\mathrm{TM}}$, part fill time, clamp force, weld lines and more can be simulated. These analyses were used to determine the best injection locations as well as the number of injection locations. Figure 15 shows the weld line analysis from Moldflow ${ }^{\mathrm{TM}}$ where the yellow cones represent injection locations and the green represents the location of weld line formations.

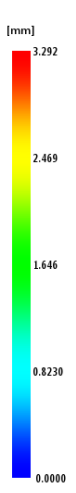

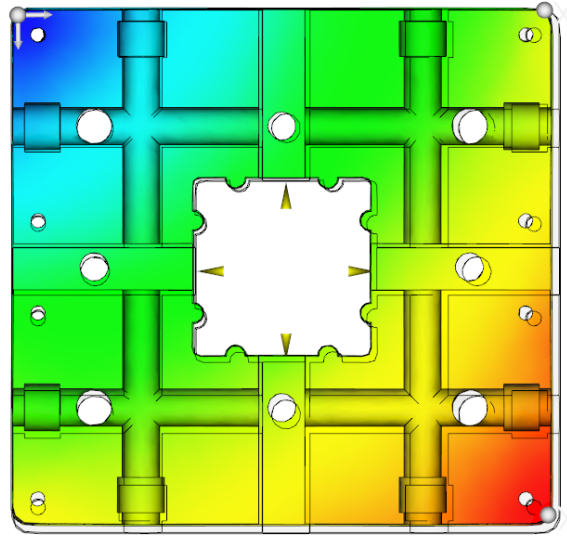

(a)

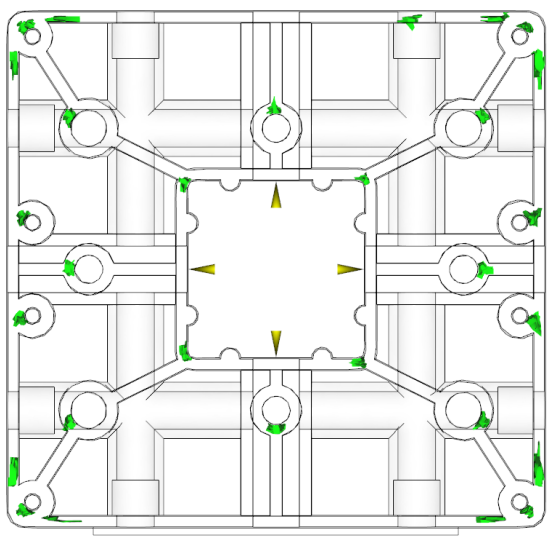

(b)

Figure 15: (a) Modular block deflection post molding (b) Weld line locations from MoldFlow analysis

\subsubsection{Mastercam Milling of the Tooling/Molds}

The CNC modular block and the mold plates were exported to Mastercam ${ }^{\mathrm{TM}}$ where manufacturing toolpaths and tooling for manufacturing the molds were defined. The mold inserts have been manufactured using a Haas CNC machine and aluminum stock while the mold plates are standard steel plates (Figure 16). These molds have been manufactured on an industrial grade threeaxis CNC machine. The milling time for the overall project is well in excess of 24 hours.
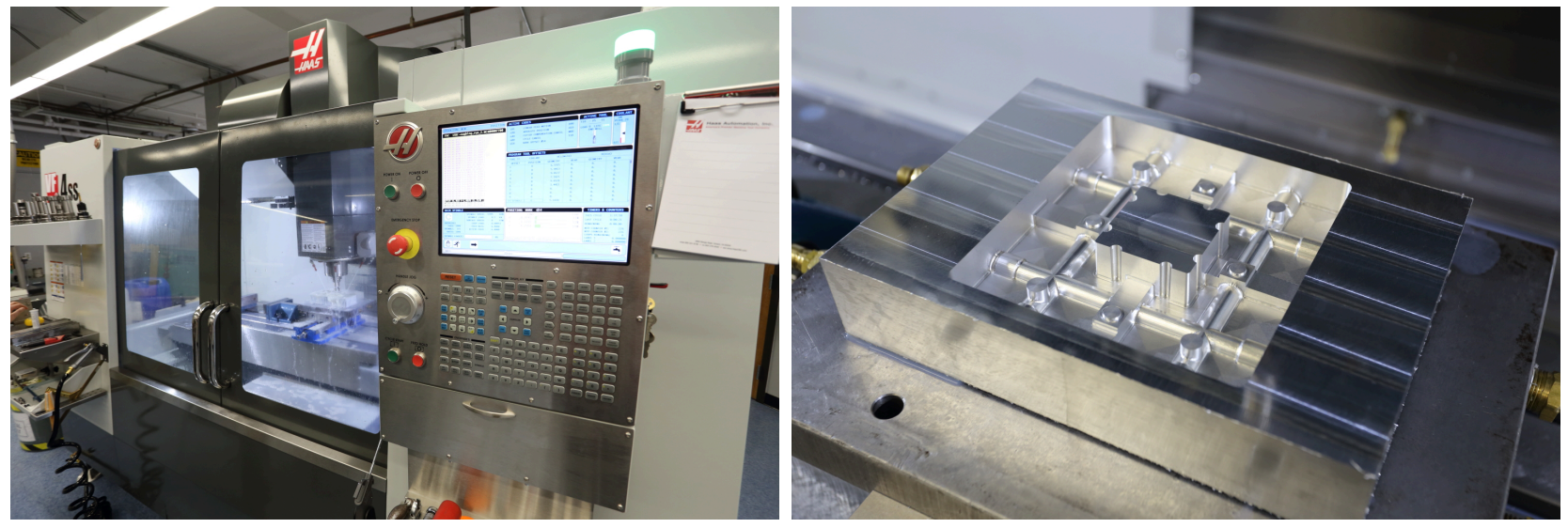

Figure 16: (left) The industrial grade Haas VF 4 SS CNC machine that was used to mill the CNC block molds. (right) The CNC block mold after the $\mathrm{CNC}$ milling process was complete. 
The modular block has recently been injection molded and was deployed as an optional component of the Introduction to Mechanical Engineering course in the Spring 2016 semester. In the Fall 2016 course offering, the modular block will be integrated fully into the curriculum. Table 1 lists the approximate bill of materials for three Cartesian CNC motion machines (1) a noncaptive motor version (2) a captive motor version with higher-end components and (3) a minimum-cost captive motor solution with cost-effective components. Table 1 indicates that the design met the majority of the goals outlined in Section 3.0.
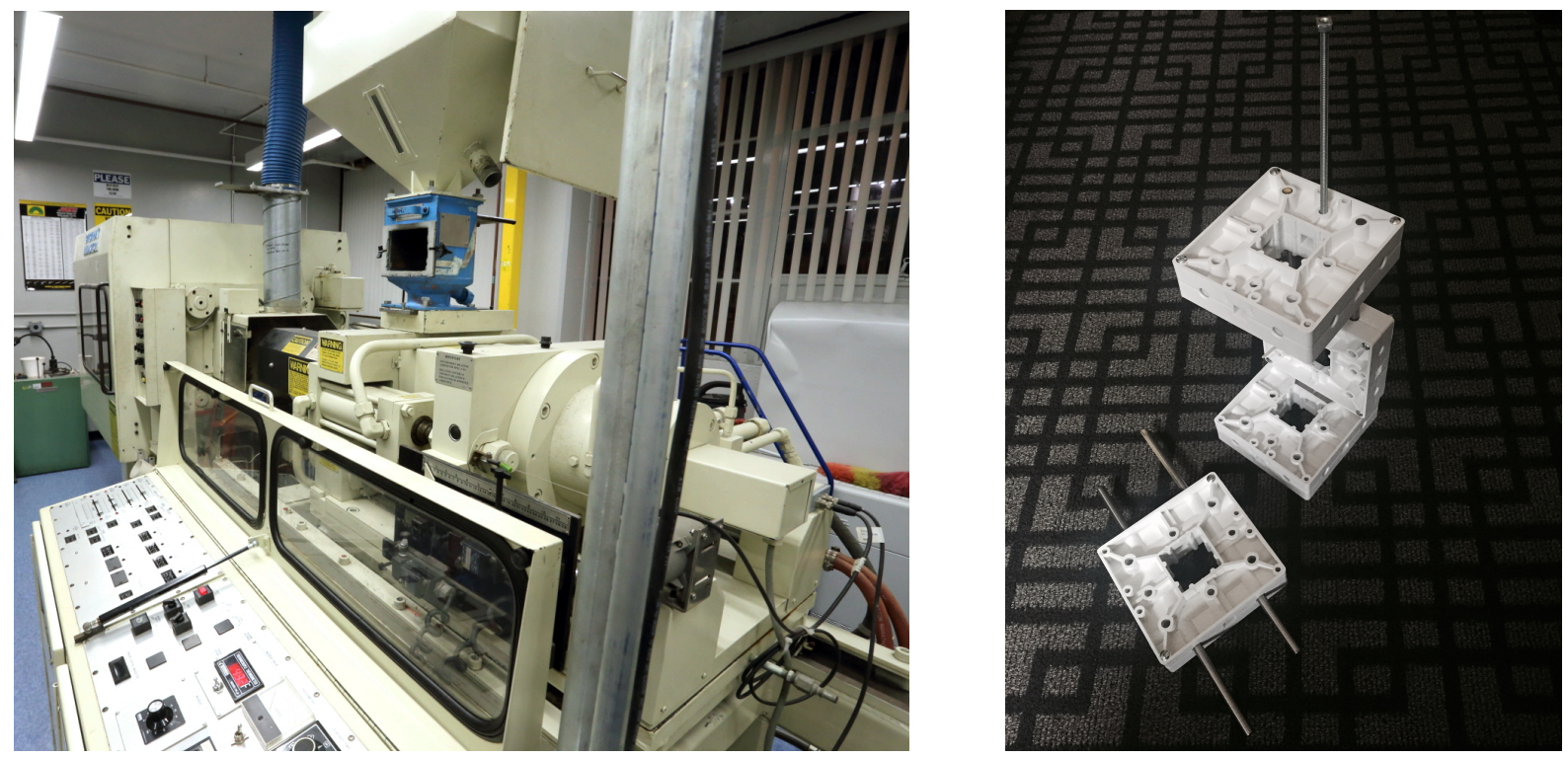

Figure 17: (left) The injection molding machine that was used for a preliminary manufacturing run (right) The injection molded CNC block assembled to make a single axis of a CNC machine.

Table 1: The approximate deployment cost for three different machine options (1) Non-captive high-end, (2) Captive, High-End and (3) Captive Economy. The items with asterisks are substituted for lower grade components in the economy version. Note this bill of materials does not include the electrical control system (controller board, enclosure and computer).

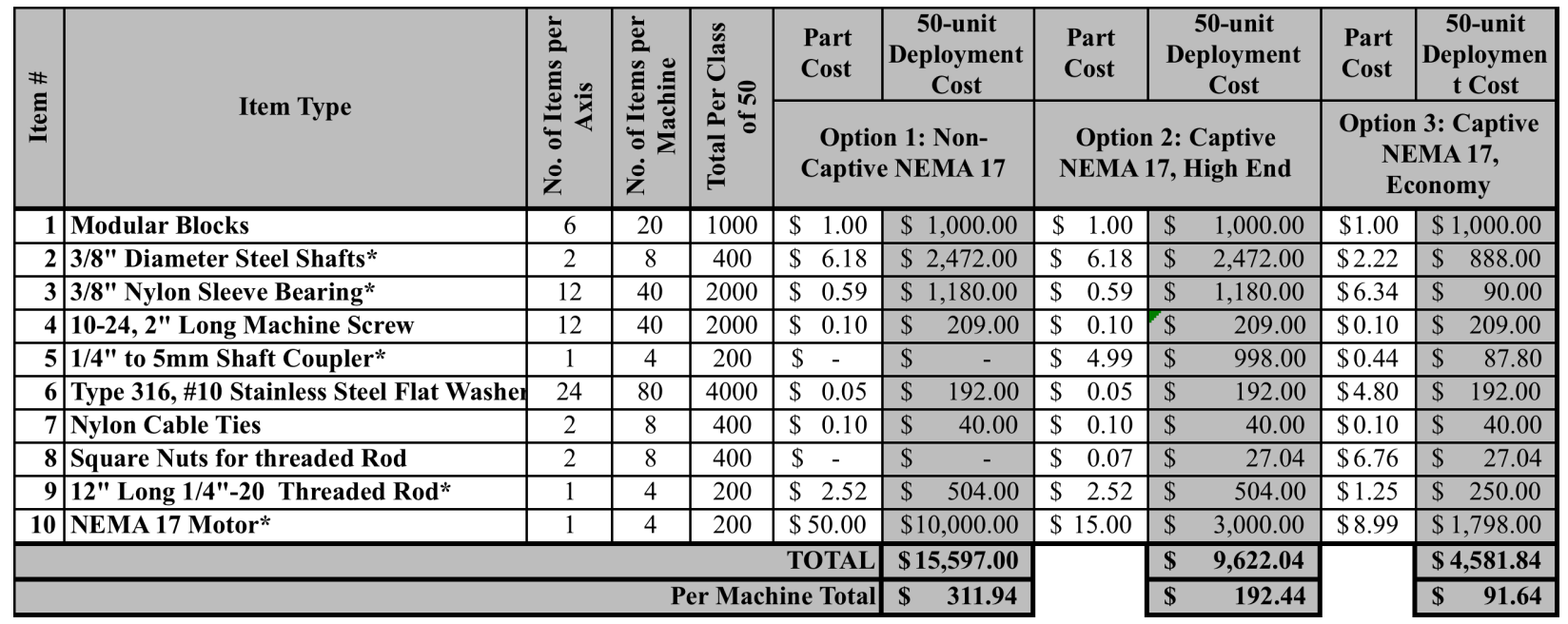




\subsection{CNC Modular Block Project: Deployment Parts List and Approximate Costs}

The modular CNC block has ben successfully manufactured using an injection molding process. As a result, the one custom unit of this project is developed and all other parts can be readily ordered or purchased. Table 1 lists the parts required as well as the unit quantities and approximate price. With economy hardware, the price of a single 3-axis CNC machine is less than $\$ 100$.

\section{PART III}

\subsection{Integrating inexpensive $\mathrm{CNC}$ machines in the engineering classroom}

The 10 off-the-shelf desktop CNC machines that are deployed at the University of Massachusetts Lowell have been used in several mechanical engineering courses over the past 2 years, including: (a) Introduction to Mechanical Engineering (b) Machine Design (c) Capstone Design (d) Aero/Wind Engineering and others. This paper focuses on the implementation details in the Introduction to Mechanical Engineering course. This freshman course was redesigned about 2 years ago to incorporate the off-the-shelf CNCs and a pilot is currently ongoing to explore the use of the new Modular CNC block in the classroom.

\subsection{Course summary Introduction to Mechanical Engineering with off the shelf CNCs}

The Spring 2014, Fall 2014, Spring 2015 and Fall 2015 offerings of the Introduction to Mechanical Engineering course introduced: Matlab programming, the engineering design process, basic engineering principles, Matlab programming and hands-on projects using $\mathrm{CNC}$ machines. The course is intended to be an experiential overview to the mechanical engineering curriculum and more broadly the mechanical engineering profession. In this paper we will present survey results from the Fall 2015 offering of the Introduction to Mechanical Engineering course and as such, focus on the details of the course here.

\subsubsection{Lecture Deployment Summary}

The Fall 2015 course had a 1-hour lecture and a 2-hour laboratory each week. The lecture comprises the entire class $(\mathrm{N}=158)$ and was held in a traditional stadium seat classroom. The lecture is divided into the following modules:

- Weeks 2-3 (9/14/15 - 9/28/15): Welcome, Orientation, Introduction to Mechanical Engineering, Introduction to Engineering Communication and Report Writing, Introduction to Matlab and plotting. The communication and plotting modules were incorporated to support the laboratory project reporting during the first part of the semester.

- Weeks 4-9 (10/5/15 -- 11/9/15): Brief introduction to Mechanical Engineering Principles. These concepts included position, velocity, acceleration, load paths, forces, moments, stress, strain, and thermo-fluid conservation laws. The presentation of theory was introductory and conceptual using examples.

- Week 10-12 (11/16/15 - 11/23/15): The Engineering design process, with a focus on Design Thinking. This included interactive lectures in design process, prototyping methods and production. The course textbook, "Making It"19 was used extensively during this portion of the course. 
- Week 13 (11/30/15): Keys to academic success as a Mechanical Engineering student. This motivational lecture is included to promote reflection on the students' exposure to Mechanical Engineering, as well as provide advice and insight into expectations in the sophomore, junior and senior years.

- Week 14 (12/7/15): End of Semester Student Expo: Students display work performed during the semester and present that work in small groups to the teaching team and to their peers.

\subsubsection{Laboratory Deployment Summary}

For the weekly laboratory, the class population is divided into 9-sections with approximately 1719 students per section. The Fall 2015 laboratory sessions were held in the newly constructed UMass Lowell Makerspace. Similar to the lecture portion of the class, the laboratory had a modular structure:

- Week 1 (9/7/15): Icebreaking activity. Build a standing structure to support 5 college textbooks at a height of 12 " above the ground using only 1 yard of packing tape and newspaper. The structure should be as light as possible.

- Weeks $2-5(\mathbf{9} / \mathbf{1 4} / \mathbf{1 5}-\mathbf{1 0} / \mathbf{5 / 1 5})$ : Logo design project. This project is intended to replicate the engineering design process from idea conception to manufacturing a final product. The students start by brainstorming logo ideas for a fictional wind energy company, use basic user studies to gain insight into promising designs, refine designs, perform a 2:1 scale drawing, digitize the logo using matlab and then CNC mill (in Week 4) the logo in a block of machinable wax (www.machinablewax.com). Once the logos are produced, the teaching team pours platinum cure silicone into the molds to produce the logo stamps. In the final week, students unveil their stamps and test them by stamping them on paper. This project is fast paced and relatively well scaffolded. Video support is also provided to the students (eg: CNC machine safety and setup: https://www.youtube.com/watch?v=Xw3duUJQIOw).

- Week 5-6 (10/5/15 - 10/12/15): Mechanical Engineering minilabs.

- The first mini-lab was an open exploration of wind energy using the KidWind Advanced Wind Experiment Kit Nacelle ${ }^{1}$. In this lab, students were given 2 hours to explore the variables affecting wind energy in groups of 4-5 students. Different wind turbine blades are provided to explore. Each group received an analogue multi-meter and several resistors. Several fans and an anemometer were provided as a source of "regulated" wind energy. The teaching team encouraged the student groups to interact with to each other to determine how to approach the lab as a whole lab section (representative of an engineering company). Student groups are strongly encouraged share data at the end of the lab (to enhance the experiential learning of careful data collection and written communication). Students explored everything from number of blades and blade pitch to gear ratio and blade size in this experiment. It was noticed that the experiment was quite uncomfortable for

${ }^{1}$ http://www.vernier.com/products/kidwind/wind-energy/kw-awxn/ 
some students who were more used to directed and heavily scaffolded learning environments.

- The second mini-lab was a heavily scaffolded exploration of tensile testing and beam bending. The tensile and bending tests were performed using Mark-10 tensile testing machines ${ }^{2}$. In this lab session student groups were given two balsa wood samples to test in tension and two balsa beams to test in 3-point bending. The goal of the lab is to experientially introduce material properties (Young's Modulus and Ultimate Stress) as experimentally determined (averaged) quantities. The second goal of this experiment was to link material properties to the structural analysis of engineering components (beams).

- Weeks 7-14 (10/19/15 - 11/30/15): Semester freshman cornerstone project. Students were assigned to follow the engineering design process to develop either:

$\circ$ A viable wind turbine design $(<16$ " diameter) and business plan for $<10 \mathrm{~W}$ applications. Students were provided a Matlab Blade Element Momentum script to analyze and virtually improve blade designs. Once the blade design was complete, student groups were given a 7" x 3" x 1.5" wax block to CNC mill a mold for their blade design. Students were encouraged to manufacture paper-mache blades using this mold. Student groups were also encouraged to explore paper mache materials and formulations to improve the blade structural strength.

○ An innovative product that would be milled (mold or product) within a 3" $\mathrm{x}$ 7" $\mathrm{x}$ 1.5 " machinable wax block. Students pursuing this project were allowed to prescribe silicone and polymorph plastics for part fabrication. The students pursuing innovation projects were also encouraged to participate in the UMass Lowell Prototyping Challenge supported by the Dean of Engineering.

The semester project is supported with "open" lab time for students to work on and develop their project. Groups are required to produce a prototype, a 5-8 page final semester report as well as a end-of-semester presentation.

- Week $14(12 / 7 / 15)$ : The students participate in an end of semester project expo at the beginning of the week.

\subsection{Introduction to mechanical engineering with In-House CNCs}

During the Spring 2016 semester, the $\mathrm{CNC}$ block was introduced into the Introduction to Mechanical Engineering course. The Spring 2016 course offering was a trailer section and had a smaller class size. The course was designed to incorporate the block into a final project involving a CNC product and Matlab computer programming. Assembling the CNC machine was optional due to the roll-out of the course material. Despite this, there were several groups that opted to assemble their own CNC machine. The course delivery is outlined below.

\footnotetext{
${ }^{2}$ http://www.mark-10.com/instruments/stands/es30.html
} 


\subsubsection{Lecture Planned Deployment Summary}

The lecture schedule for Spring 2016 includes:

- Week 2 (1/25/16): Welcome, What is Mechanical Engineering

- Week 3-4 (2/1/16 - 2/8/16): Overview of the Engineering Design Process

- Week 5 (2/15/16): Introduction to Engineering Communication

- Week 6 - 9 (2/22/16 - 3/21/16): Mechanical Engineering Concepts and Analysis (position, velocity, acceleration, stress, strain and conservation laws).

- Week 9-11 (3/28/16 - 4/11/16): Engineering design process part II, prototyping and manufacturing processes.

- Week 12 (4/18/16): Open lab time for final project.

- Week 13 (4/25/16): Open lab time for final project.

- Exam week: Project Expo.

\subsubsection{Laboratory Planned Deployment Summary}

The laboratory schedule for Spring 2016 includes:

- Week 1 (1/18/16): Icebreaker activity - tallest single sheet paper structure that can support a textbook.

- Weeks 2-5 (1/25/16 - 2/15/16): Logo project design, analysis, manufacturing and testing.

- Weeks 5-7 (2/15/16 - 3/29/16): Mechanical Engineering and CNC Group Labs. This included a beam bending lab as well as $2 \mathrm{x}$ CNC related laboratories, (1) to explore programmable position, motion, etc. and (2) to explore sequentially programmed motion through an image replication project. Students for this project were tasked to import an image into matlab and process it (threshold, etc.) to produce a "dotted" replica on the CNC machines. An example result is shown in Figure 18.

- Weeks 8 - 13 (3/29/22 - 4/25/16): CNC modular block based final project. Students designed (and had the option to build) a CNC modular block platform that responds to a human need. Eg: Vegetable chopper for the elderly, two-tone wood-burning CNC image generation, and autonomous cookie makers, etc. See Figure 19 for an example.
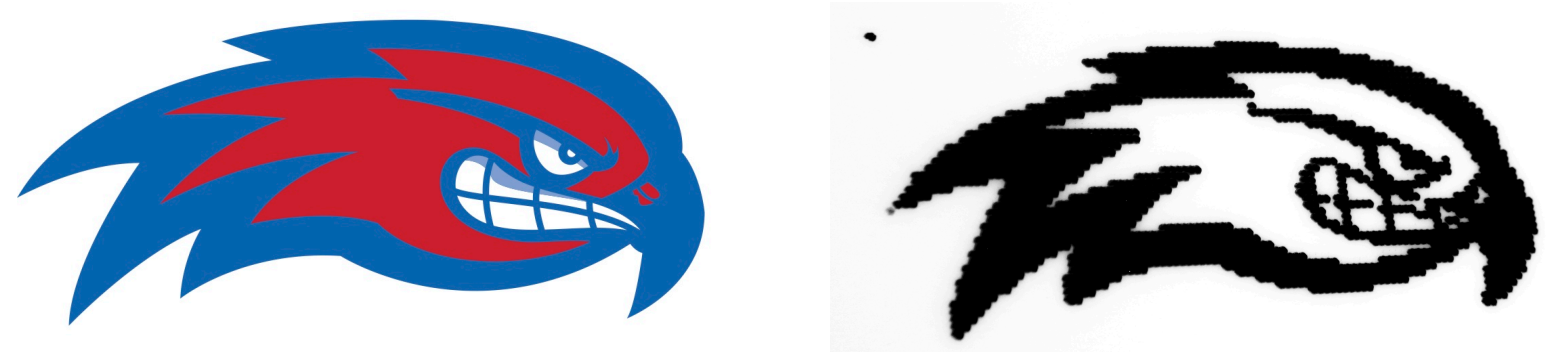

Figure 18: (left) The UMass Lowell Riverhawks Logo (reproduced with permission) (right) A student project result for the second CNC laboratory. Students developed a Matlab program that imported a jpeg image, processed it, and then used the CNC machine to place dots on the paper. 

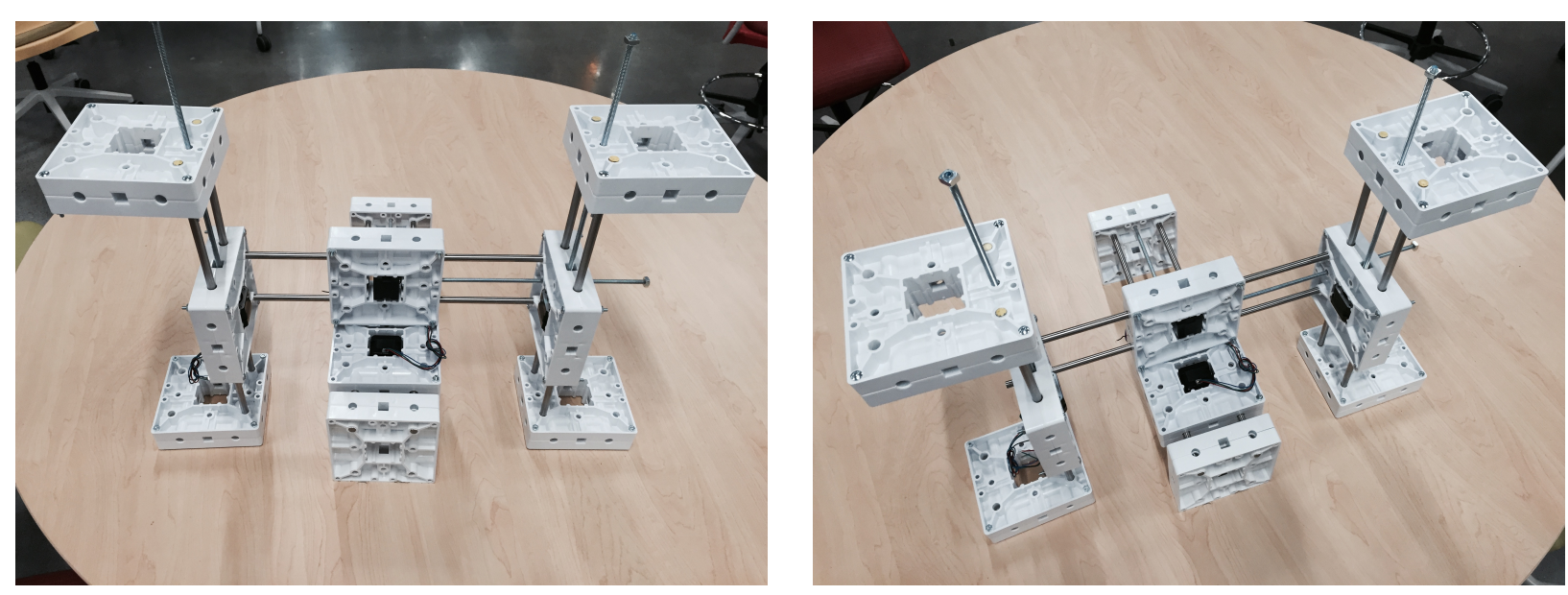

Figure 19: A CNC machine prototype built by an Introduction to Engineering Student. Student groups were given the opportunity to construct their own CNC motion block machines.

\subsection{Student Motivation: Introduction to Mechanical Engineering}

It is hypothesized that integrating CNC machines in the classroom will improve student motivation towards engineering. Student motivation is assessed using the SIMS (Situational Motivation Survey, Guay et al. ${ }^{9}$ ) via weekly surveys at the end of class/laboratory periods.

\subsection{Introduction to SIMS survey \& class data collection}

Student motivation has been shown to have an impact on their educational outcomes ${ }^{10-15}$. Motivation is a continuum, with amotivation existing at the lower end of the scale and intrinsic or internally directed motivation on the other end of the scale ${ }^{16}$. The SIMS survey consists of 16 questions that are used to classify motivation level by weighting the student responses to questions categorized by the following descriptors (descriptions below from Vaillant et al. ${ }^{5}$ ):

- Amotivation ${ }^{5,9,16}$ : A condition in which learners find no reason to engage in a task, and they disconnect their actions from any outcome.

- External Regulation ${ }^{5,9,16}$ : External pressures, in the form of rewards, praise, demands, or punishments, drive participation in an activity.

- Identified Regulation ${ }^{5,9,16}$ : Students identify importance, usefulness, or value in a task, and link the activity to personally desirable goals or outcomes.

- Intrinsic Motivation ${ }^{5,9,16}$ : Participation in a task or activity that is described by inherent enjoyment or interest.

The self-determination index (SDI) is used to summarize an overall motivation level. The SDI is computed using the the responses to the SIMS survey questions and the following formula ${ }^{5,9,16}$ :

$$
S D I=2(\text { Intrinsic })+1(\text { Identified })-1(\text { External })-2(\text { Amotivation })
$$

Higher SDI values indicate more internally derived motivation that is linked to more meaningful learning experiences ${ }^{17,18}$. The questions on the SIMS survey follow those presented by Guay et al. ${ }^{9}$ 
In addition to the SIMS survey questions, the following open questions were asked each week ${ }^{15}$ :

1. How well do you feel you did over the past week in the course? How do you know?

2. Thinking about your experience over the past week in the course, what particular activities and/or interactions both inside and outside the classroom stand out for you?

3. Thinking about your experience over the past week in the course, what particular emotions and/or thoughts about the course both inside and outside the classroom stand out for you?

4. What factors contributed to your motivation over the past week in the course?

5. Please reflect on the extent to which your experience over the past week in the course was personally relevant for you now and in the future.

The SIMS survey ${ }^{9}$ was administered on paper using an optical mark recognition (OMR) friendly survey during the Fall 2015 Introduction to Mechanical Engineering class and is currently being administered in the Spring 2016 Introduction to Mechanical Engineering offering.

\subsection{SIMS Survey Collection and Processing Methods}

Informed consent forms are collected from participants at the start of the semester. The SIMS Survey responses are then collected on paper every week at the end of the laboratory session. Paper based SIMS surveys are scanned by the Graduate Research assistant and stored in a safe place. The scanned pages are then processed using a custom MATLAB OMR code to convert the responses into raw data for processing.

\subsection{6-Question SIMS Survey Results and Discussion.}

The 16-question survey was processed cumulatively for the Fall 2015 semester. The final paper will also show cumulative results for the first half of Spring 2016 semester as well as the individual tracking of motivation during the Fall 2015 semester.

The results of the survey show a strong student response to the survey (at least a $15 \%$ response rate most weeks, Figure 20). The response rate is higher than previous years of this project (Vaillant et al. ${ }^{5,6}$ ).

The SIMS survey results are summarized for the Fall 2015 semester in Figures 21 and 22. The results generally show strong internally derived motivation (intrinsic and identified) each week. The amotivation is consistently low throughout the semester, which is a positive indicator of the students' motivations toward hands-on activities and classes. The self-determination index shows strong positive motivation response to early in the semester activities - in particular in week 4 when the $\mathrm{CNC}$ machines are first used. Other peaks include tensile and bending tests in week 6 and then once again showing peaks at weeks 11 and 12 when the CNC machines were used again to mill wind turbine blade molds and innovation projects. Conversely, lower motivational responses were observed in weeks 8 - 10 when the majority of groups were defining their semester project products and working with Matlab to analyze and digitize designs. Overall, the motiva- 
tion data show strong connection between the $\mathrm{CNC}$ and laboratory hands-on activities and the motivation response of the students.

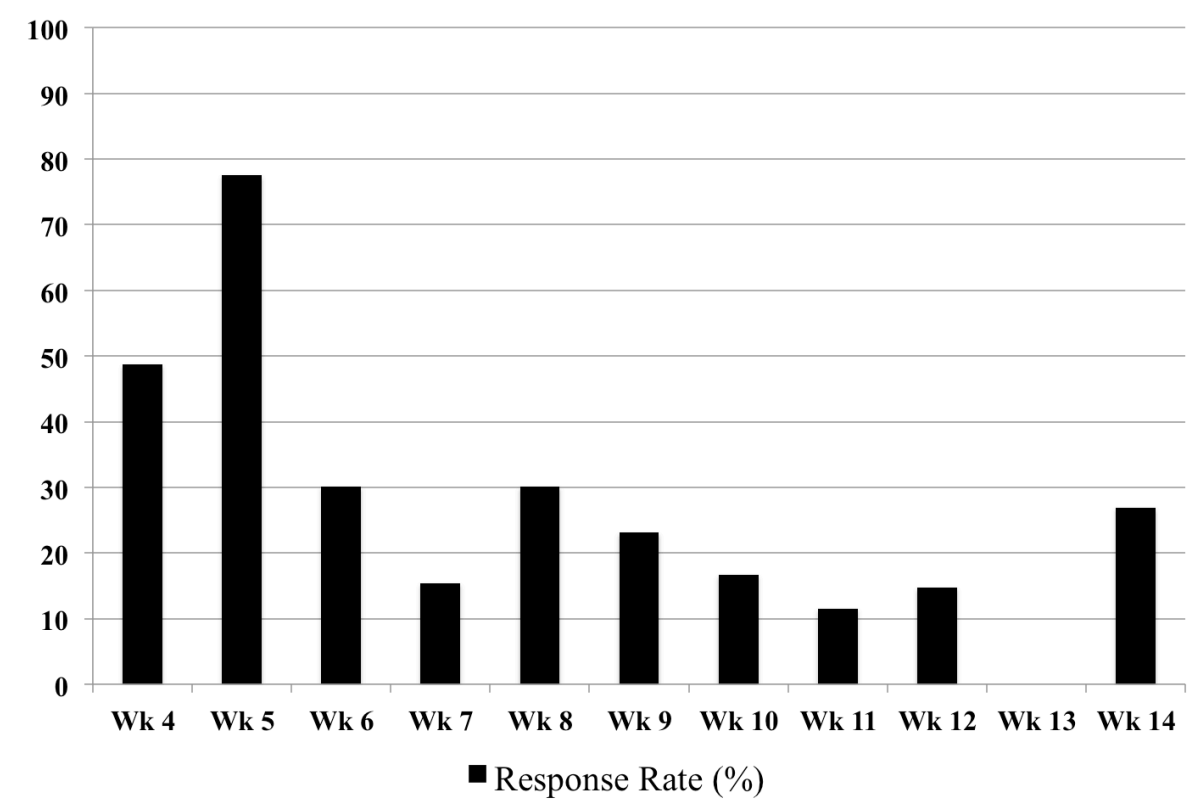

Figure 20: Overall response rate each week based on total number of students in the class. Most weeks achieved a response rate greater than 15\%. Note that week 13 corresponds to Thanksgiving break when no survey data was collected.

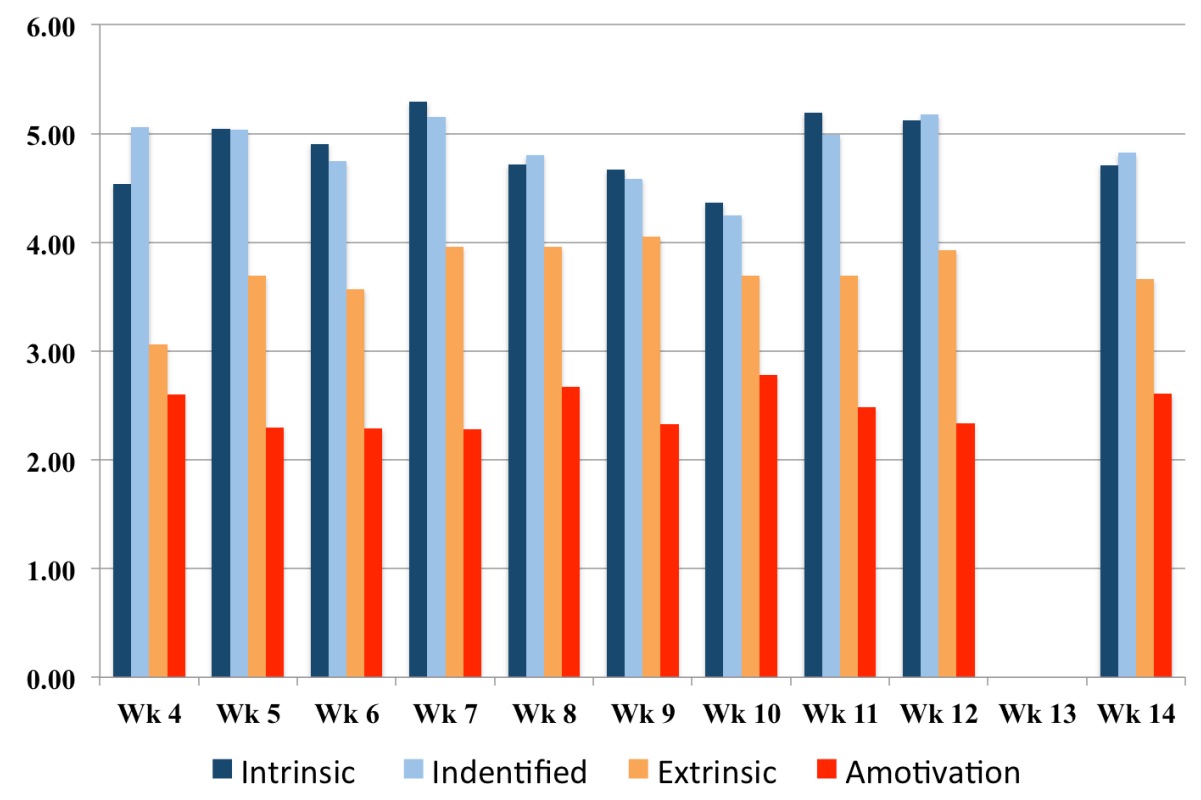

Figure 21: The SIMS survey results for each week in the Fall 2015 Introduction to Mechanical Engineering course. Note that the Intrinsic and identified motivation are high for most weeks. 


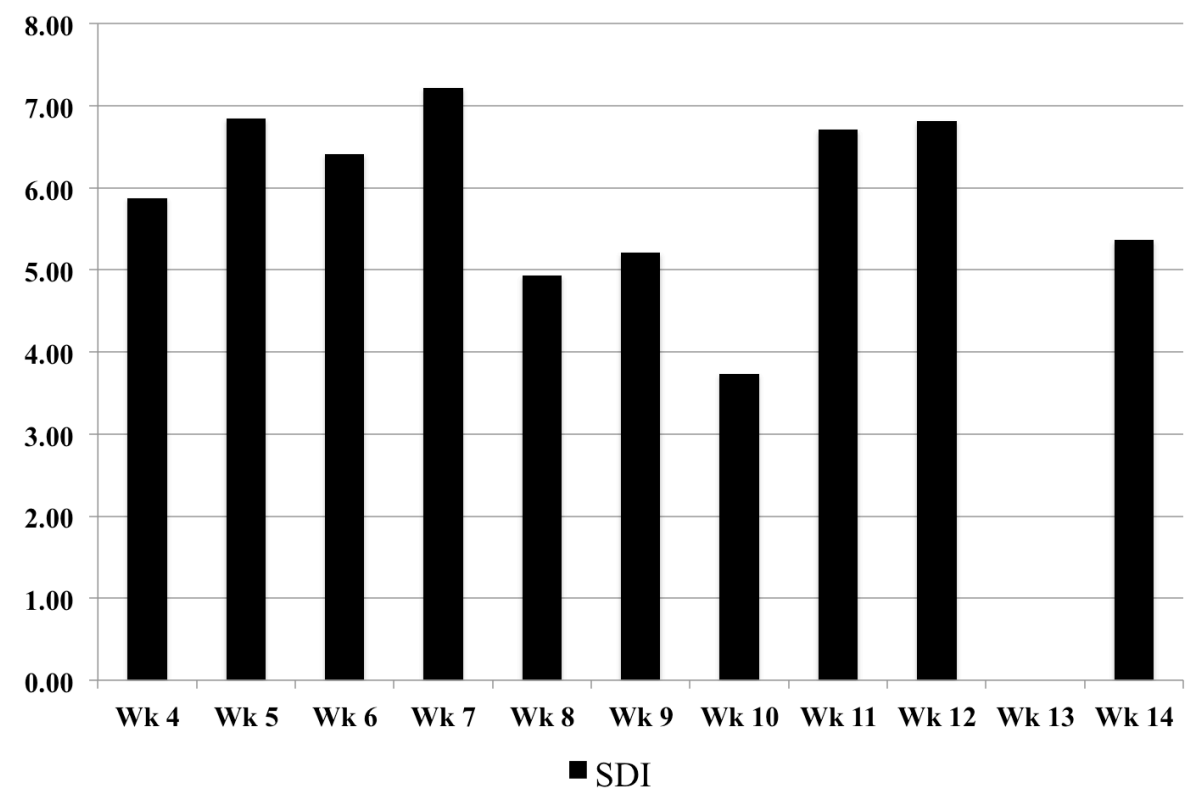

Figure 22: The SIMS Self Determination Index (SDI) results for each week in the Fall 2015 Introduction to Mechanical Engineering course. These results indicate strong motivation among the students. Lower motivation was observed in weeks 8-10 when students were performing final project product brainstorming and performing subsequent analysis using Matlab.

The results of the Fall 2015 Introduction to Engineering course motivation study indicate that students had positive motivation towards hands-on activities in the laboratory (spring 2016 results are not available at this time). In weeks 4, 10,11 and 12 these activities for a select group of students involved CNC machine use. During weeks 5 and 6 the students were performing handson laboratories, including KidWind wind turbine testing and beam bending. These results show a strong motivational preference for hands-on activities during the laboratory. The hope is that these positive motivation results continue with the integration of the modular block CNC component.

\subsection{Written Question Survey Response: Results and Discussion.}

In addition to the SIMS survey, the students were also given the opportunity to response to open questions. These questions shed some light on the attitudes and responses to the projects. A selection of these comments is presented below for different weeks.

\section{Week 5}

- I was excited to finally use the Matlab Program, but a bit overwhelmed when I didn't know what to do.

- Please make Instructional videos for the in-class assignments.

- Having to use simple materials and tools are very important in the prototyping process.

- Wind Turbine Project: Frustration, Overwhelming 


\section{Week 6}

- I enjoyed working with different materials in stress lab

\section{Week 10}

- Stand Out activity: Milling with CNC Machine for innovation project.

- Motivation: The fact that we were given freedom to choose what we do the project on.

- Excited about making the mold.

\section{Week 13}

- I have learned a lot in the course and have a relatively good experience in the field. Even more excited to pursue engineering.

This selection of comments aligns well with the conclusions derived from the SIMS motivation survey responses. The students value the autonomy as well as the hands-on experience of working with $\mathrm{CNC}$ machines. The students report positive experiences surrounding the hands-on portion of the labs and sense of accomplishment that a CNC based course can provide. Too much autonomy however resulted in frustration and confusion as reported for the wind turbine lab.

\subsection{Conclusions}

This paper presents the Hands-On MADE for ME project that is focused on integrating CNC educational experiences in a Mechanical Engineering curriculum. The use of off-the-shelf kit-based CNC machines is a viable approach for Mechanical Engineering education when ample support resources are available for laboratory setup and operation. An education specific modular block design for building CNC configurations was presented in this paper. This block aims to provide a rapid deployment solution for CNCs in the laboratory through specific design trade-offs. The resulting block design is low cost resulting in a CNC machine with a minimum number of parts and a low deployment cost. This block will be deployed in the Spring 2016 semester and presented in the final version of the paper and in the poster.

Student motivation surrounding hands-on CNC activities in the Introduction to Engineering laboratory was examined. The results indicate that students present positive motivation towards hands-on CNC activities in the classroom. Furthermore, the inclusion of CNC related activities (milling Logos and molds for the semester project), had a positive impact on the students' motivation towards the course and/or mechanical engineering.

\section{Acknowledgements}

The research team would like to thank Professor J. Stolk for his valuable insight and assistance with the deployment of the SIMS surveys for assessing students' motivation. This material is based upon work supported by the National Science Foundation under Grant No. 1245657. Any opinions, findings, and conclusions or recommendations expressed in this material are those of the author(s) and do not necessarily reflect the views of the National Science Foundation. 


\section{References}

[1] Brereton, M., Sheppard, S. \& Leifer, L. "Students connecting engineering fundamentals and hardware design: Observations and implications for the design of curriculum and assessment methods," in 1995 Frontiers in Education Conference.

[2] Wittemyer, R., McAllister, B., Faulkner, S., McClard, A. \& Gill, K. "MakeHers: Engaging Girls and Women in Technology through Making, Creating, and Inventing.” Intel Corporation, 2014.

[3] J. Vaillant, "Analysis, Implementation, and Educational Impact of Digital Fabrication Techniques Using Desktop Machines," MS Thesis, University of Massachusetts Lowell, August 2014.

[4] Vaillant, J.J., Hansen, C.J., Johnston, S.P., Shina, S.G., Willis, D.J., Design and Implementation of an Inexpensive Laboratory for Providing Hands-On Design Prototyping and Manufacturing Experiences to Engineering Students, presented at ASEE's $122^{\text {nd }}$ Annual Conference and Exposition, Seattle, WA, June $14^{\text {th }}-17^{\text {th }}$ 2015 .

[5] Vaillant, J.J., Hansen, C.J., Stolk, J.D., Johnston, S.P., Shina, S.G., Willis, D.J., "Examining the Integration and Motivational Impact of Hands on Made4Me: Hands-on Machining, Analysis and Design Experiences for Mechanical Engineers," presented at ASEE's $122^{\text {nd }}$ Annual Conference and Exposition, Seattle, WA, June $14^{\text {th }}-17^{\text {th }} 2015$.

[6] J.Vaillant, C.J.Hansen, J.Stolk, S.Johnston, S.Shina, D.J.Willis, "Hands-On Made 4 ME: The impact of CNC technology in the early engineering curriculum", Paper in ASEE's $121^{\text {st }}$ Annual Conference and Exposition, Indianapolis, IN, NSF-Grantees special poster session, ASEE National Conference, June 2014.

[7] D.J.Willis and J.Vaillant, Designing a Scalable Mechanical Engineering Freshman Experience for Relevant and Engaging Hands-On Experiences, Presented at the 2015 ASEE Northeast Region Conference, Boston, MA, April 30th-May 2nd 2015.

[8] J. Martell, W. Kelschinsky, A. Schiano, J.Vaillant and D.J.Willis, Computer Numerically Controlled Machine Development for Educational Applications: A Senior Design Project, Presented at the 2015 ASEE Northeast Region Conference, Boston, MA, April 30th-May 2nd 2015.

[9] Guay, F., Vallerand, R.J., \& Blanchard, C. "On the assessment of state intrinsic and extrinsic motivation: The situational motivation scale (SIMS).” Motivation and Emotion, vol. 24, pp. 175-213, 2000.

[10] Amabile, T.M. “The social psychology of creativity: a componential conceptualization,” Journal of Personality and Social Psychology, vol. 45, no. 2, pp. 357-376, 1983.

[11] Garcia, T. and P. R. Pintrich, "The effects of autonomy on motivation and performance in the college classroom," Contemporary Educational Psychology, vol. 21, no. 4, pp. 477-486, 1996.

[12] Pintrich, P. R. "The role of motivation in promoting and sustaining self-regulated learning," International Journal of Educational Research, vol. 31, pp. 459-470, 1999.

[13] Pintrich, P. R., and E. V. De Groot, "Motivational and self-regulated learning components of classroom academic performance," Journal of Educational Psychology, vol. 82, no. 1, pp. 33-40, 1990. 
[14] Stefanou, C., J. D. Stolk, M. Prince, J. Chen, and S. M. Lord, "Self-regulation and autonomy in problem-and project-based learning environments." Active Learning in Higher Education 14(2), 109-122, 2013.

[15] Stolk, J. and J. Harari, "Student motivations as predictors of higher-level cognitions in project-based classrooms," Active Learning in Higher Education, vol. 15, no. 3, pp. 231-247, 2014.

[16] Ryan, R. M., \& Deci, E. L. "Self-determination theory and the facilitation of intrinsic motivation, social development, and well-being." American Psychologist, vol. 55, pp. 68-78, 2000.

[17] Vansteenkiste, M., W. Lens, and E. L. Deci, "Intrinsic versus extrinsic goal contents in self-determination theory: Another look at the quality of academic motivation." Educational Psychologist 41(1): 19-31, 2006.

[18] Wolters, C. A., “Self-regulated learning and college students' regulation of motivation.” Journal of Educational Psychology 90(2): 224-35, 1998.

[19] Lefteri, C., "Making It! Manufacturing Techniques For Product Design”, Laurence King Publishing; $2^{\text {nd }}$ Edition, 2012. 